\title{
Met-regulated expression signature defines a subset of human hepatocellular carcinomas with poor prognosis and aggressive phenotype
}

\author{
Pal Kaposi-Novak, Ju-Seog Lee, Luis Gòmez-Quiroz, Cédric Coulouarn, \\ Valentina M. Factor, and Snorri S. Thorgeirsson
}

Laboratory of Experimental Carcinogenesis, Center for Cancer Research, National Cancer Institute, NIH, Bethesda, Maryland, USA.

\begin{abstract}
Identification of specific gene expression signatures characteristic of oncogenic pathways is an important step toward molecular classification of human malignancies. Aberrant activation of the Met signaling pathway is frequently associated with tumor progression and metastasis. In this study, we defined the Met-dependent gene expression signature using global gene expression profiling of WT and Met-deficient primary mouse hepatocytes. Newly identified transcriptional targets of the Met pathway included genes involved in the regulation of oxidative stress responses as well as cell motility, cytoskeletal organization, and angiogenesis. To assess the importance of a Met-regulated gene expression signature, a comparative functional genomic approach was applied to 242 human hepatocellular carcinomas (HCCs) and 7 metastatic liver lesions. Cluster analysis revealed that a subset of human HCCs and all liver metastases shared the Met-induced expression signature. Furthermore, the presence of the Met signature showed significant correlation with increased vascular invasion rate and microvessel density as well as with decreased mean survival time of HCC patients. We conclude that the genetically defined gene expression signatures in combination with comparative functional genomics constitute an attractive paradigm for defining both the function of oncogenic pathways and the clinically relevant subgroups of human cancers.
\end{abstract}

\section{Introduction}

The application of microarray-based gene expression profiling in cancer research has provided mechanistic insights into the oncogenic process and contributed to the molecular classification of malignancies (1). Transcription profiles from hundreds of microarray experiments have recently been integrated into large, multiplex data sets (2), and various reverse engineering methods have been used to decipher functionally significant gene networks (3). An important contribution from these studies is the identification of well-defined, coregulated transcriptional modules that are beginning to provide a molecular explanation of disease pathogenesis and consequently may hold great therapeutic significance (4).

An alternative approach to identifying relevant molecular events of malignant transformation and tumor progression is to characterize both known and suspected oncogenic pathways and to establish their specific gene expression signatures (5). Although the presence of these expression signatures is frequently obscured by the etiological complexity of the human tumors, they could be revealed using in vitro experimental systems and genetically modified animal models, in which the number of experimental variables could be rigorously controlled (6). Cross-comparison of

Nonstandard abbreviations used: CCP, compound covariate predictor; HCC, hepatocellular carcinoma; LDA, linear discriminator analysis; LEC, Laboratory of Experimental Carcinogenesis, National Cancer Institute; LOOCV, leave-one-out crossvalidation; MVD, microvessel density; $\mathrm{NC}$, nearest centroid; NN, nearest neighbor; SVM, support vector machine.

Conflict of interest: The authors have declared that no conflict of interest exists. Citation for this article: J. Clin. Invest. 116:1582-1595 (2006). doi:10.1172/JCI27236. the well-defined expression signatures with transcription profiles of human tumors may also improve the current understanding of the oncogenic process.

The HGF/Met signaling pathway regulates multiple cellular functions, including cell proliferation, motility, differentiation, tubulogenesis, and angiogenesis $(7,8)$. The importance of intact $\mathrm{HGF} /$ Met signaling during embryogenesis is clearly demonstrated in mouse models, where homozygous deletion of either $H g f(9)$ or Met (10) is embryonic lethal. HGF/Met signaling also affects liver biology at several levels (11). In $H g f \mathrm{KO}$ mice the hepatic plate is underdeveloped (9), while in adult livers Met activation alleviates chemically induced fibrosis (12) and protects hepatocytes from CD95-mediated apoptosis $(13,14)$. Increased HGF levels after partial hepatectomy promote liver regeneration by enhancing proliferation of mature hepatocytes and hepatic progenitor cells (15).

In addition to its physiological functions, the protooncogene $M E T$ is a master regulator of metastasis formation, tumor invasion, and angiogenesis $(8,16)$. In various types of human carcinomas, including papillary renal cancer and gastric and small cell lung cancer, activating mutation, amplification, and overexpression of the MET gene have been associated with "metastatic phenotype" and poor prognosis (17). Consequently, Met is regarded as a promising molecular target for antimetastasis therapies (18). In human hepatocellular carcinoma (HCC), overexpression and mutation of the MET gene are associated with intrahepatic metastases and vascular invasion, 2 of the most important clinical findings determining disease outcome $(17,19)$.

In the present study we have adopted a global genomic approach to comprehensively define the effect of HGF/Met signaling on the 


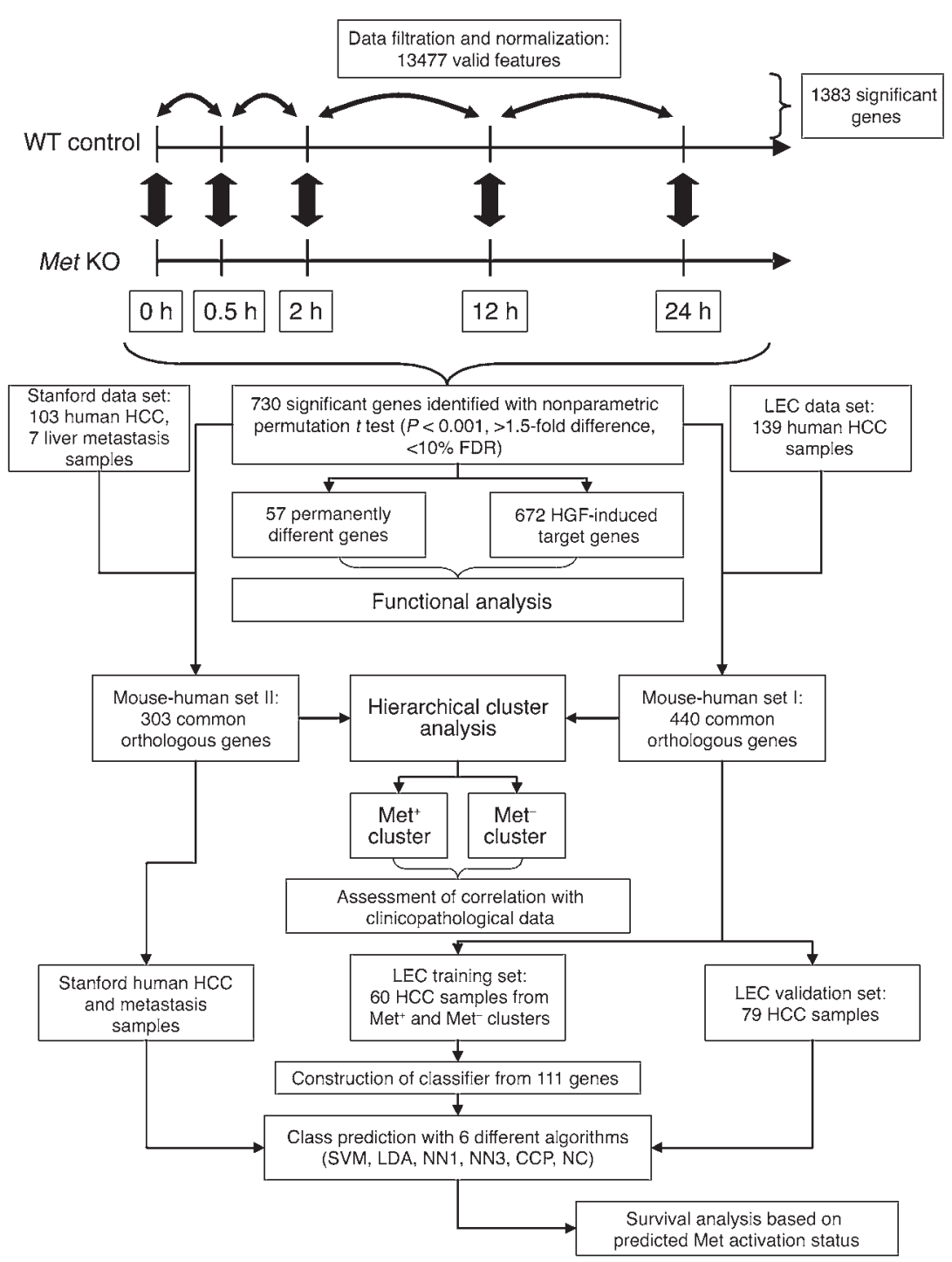

\section{Figure 1}

Diagram of data analysis. HGF/Met-regulated genes were identified by comparison of expression profiles from WT and Met KO hepatocytes. Expression of common orthologous HGF target genes was also assessed in 2 independent HCC data sets. The classifier was constructed from cross-species-conserved HGF/Met target genes to predict patient survival. Results were validated with multiple prediction algorithms on separate training and validation sets of HCC samples. FDR, false discovery rate. hepatocyte transcriptome. First, we assessed the HGF-induced gene expression patterns in primary hepatocytes isolated from Met KO (20) and WT mice and identified several potential Met target genes as well as novel regulatory functions of Met. We next applied comparative functional genomic analysis to evaluate the importance of the Met-regulated gene expression signature in the pathogenesis of human HCC. A study of 2 independent human data sets revealed that the Met-regulated gene expression signature characterizes a subgroup of HCC with aggressive phenotypic traits and poor prognosis.

\section{Results}

Characterization of the Met-regulated gene expression signature in primary hepatocytes. To identify HGF/Met-regulated genes, we performed expression microarray analysis after inducible activation of Met receptor in primary cultures of hepatocytes established from WT and Met conditional KO mice. Total RNA was isolated from untreated hepatocyte cultures as well as from cultures treated with $50 \mathrm{ng} / \mathrm{ml}$ of HGF for $0.5,2,12$, or 24 hours. RNA collected from these experiments was converted to fluorescently labeled cDNA and used for hybridizations of oligonucleotide microarrays con- taining 21,997 features representing 19,140 unique mouse genes. After normalization of the data, 13,477 features with a sufficient number of valid expression values were selected for further analysis as described in Methods.

To define the set of HGF/Met-regulated genes, we compared experiments using a multivariate permutation $t$ test at each time point. In total, 730 unique features showed significant $(P<0.001)$ and at least 1.5 -fold expression differences between the 2 genotypes. As the only variable at these comparisons was the presence or absence of intact Met receptor, we could conclude that the expression of significant genes was regulated in a Met-dependent manner. The diagram in Figure 1 gives a summary of the data analysis strategy applied to select the significant HGF-regulated genes.

The set of differentially expressed genes could be further divided into 2 major categories. The first category was represented by genes that showed permanent transcriptional changes in Met $\mathrm{KO}$ primary hepatocytes. Thus, expression of 60 genes was found to be altered in Met KO cultures at the 0 time point (after overnight incubation), and 57 of them remained differentially expressed during 24 hours of HGF exposure as compared with control cultures $(P<0.005)$ (Figure 2A). The presence of the permanent gene expres- 
A

\section{Met WT}

KO

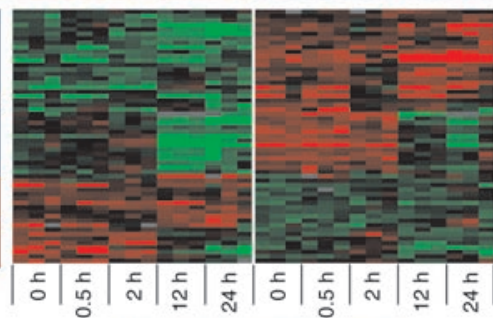

B
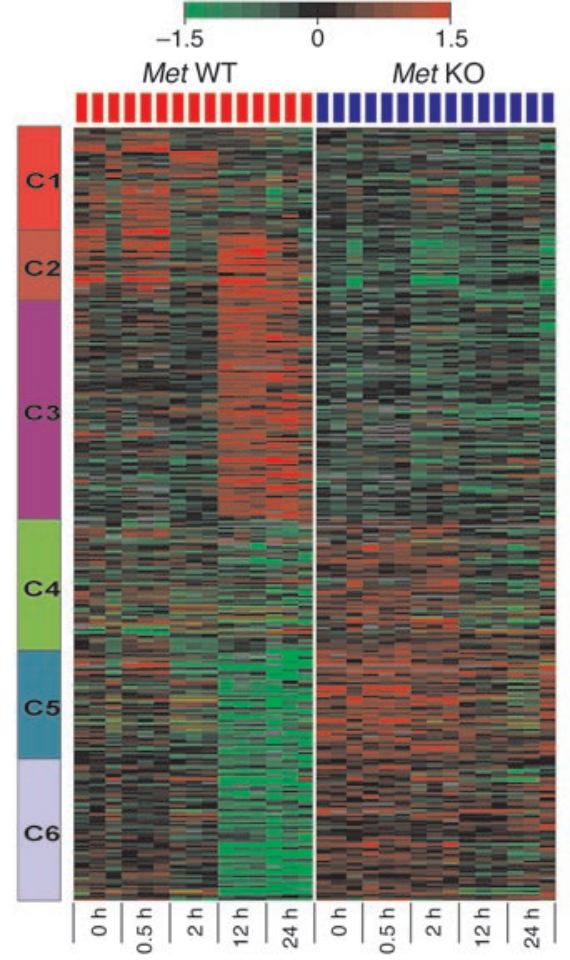

C

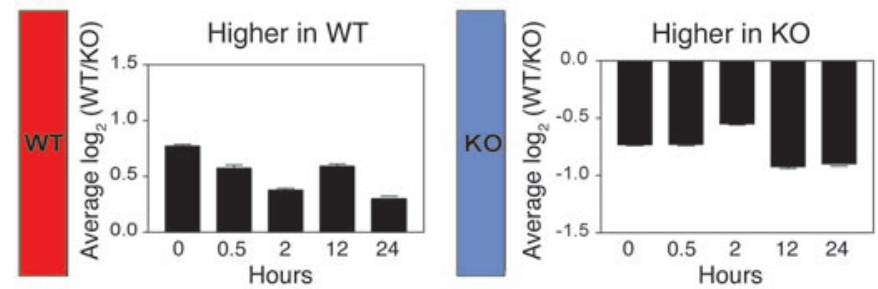

C1
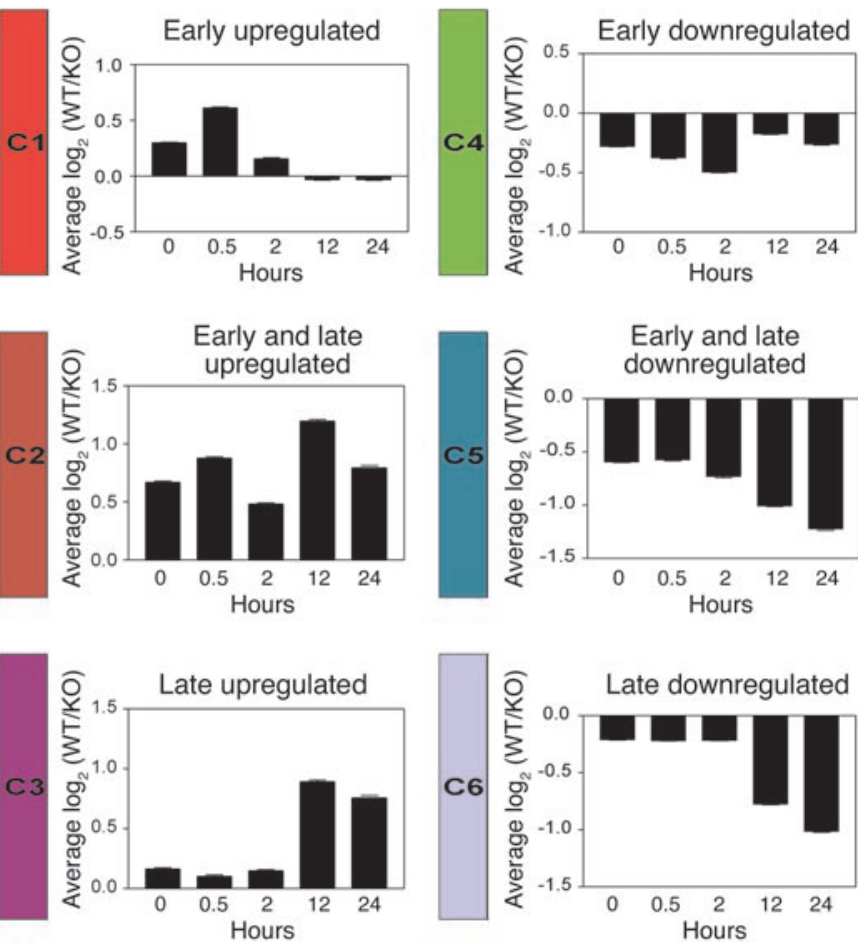

\section{Figure 2}

Gene expression patterns of HGF-regulated genes in primary mouse hepatocytes. Gene expression ratios from duplicated dye-swapped hybrid-

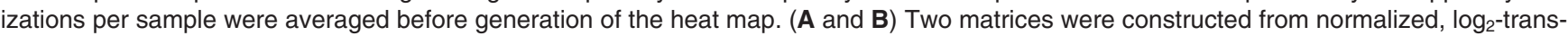
formed expression ratios of genes with permanent (A) and HGF-induced (B) expression differences between the WT and Met KO cells. Red and blue columns at the top represent triplicate WT and Met KO samples, respectively, from the consecutive treatment points $(0,0.5,2,12$, and 24 hours). Rows represent individual genes. (C) HGF/Met-dependent genes also formed clusters with different temporal induction patterns. Bar graphs show the mean expression differences \pm SEM between the WT and Met KO samples in 6 gene clusters with expression peaks at early $(\mathrm{C} 1, \mathrm{C} 4)$, late $(\mathrm{C} 3, \mathrm{C} 6)$, or both early and late $(\mathrm{C} 2, \mathrm{C} 5) \mathrm{HGF}$ treatment points. Other gene clusters displayed permanently higher expression levels either in the WT or in the Met KO samples.

sion changes implies that in the absence of Met signaling, KO cells undergo a genotype-specific transcriptional adaptation.

As expected, the majority of significant genes (672/730) were only detected in control hepatocytes after HGF treatment, since Met KO cells did not exhibit a specific response to HGF. The genes in this second category could be further separated on the basis of their temporal expression patterns. Up- or downregulated genes were divided into early and late target gene clusters, as they displayed maximal expression differences between the genotypes after a short-term (a half hour or 2 hours) or long-term ( 12 or 24 hours) HGF treatment. The heat map image created with the mean-centered $\log _{2}$-transformed expression ratios of the significant Metregulated genes clearly demonstrates the presence of clusters with the distinctive temporal regulation and the reproducibility of the data in replicate experiments (Figure 2, B and C).

To validate the specificity of the Met targets, we also compared gene expression between HGF-treated and untreated control primary hepatocytes as well as between control cells treated at consecutive time points. This approach yielded 1,383 differentially expressed genes using the same selection criteria as in the previous comparisons. Notably, some of these genes did not show significant expression differences between the WT and KO hepatocytes, as they probably reflect common adaptive responses to the culture conditions with time. However, 353 from the previously determined Met targets were also identified with both selection strategies. In most cases, the timing and magnitude of the most significant responses 

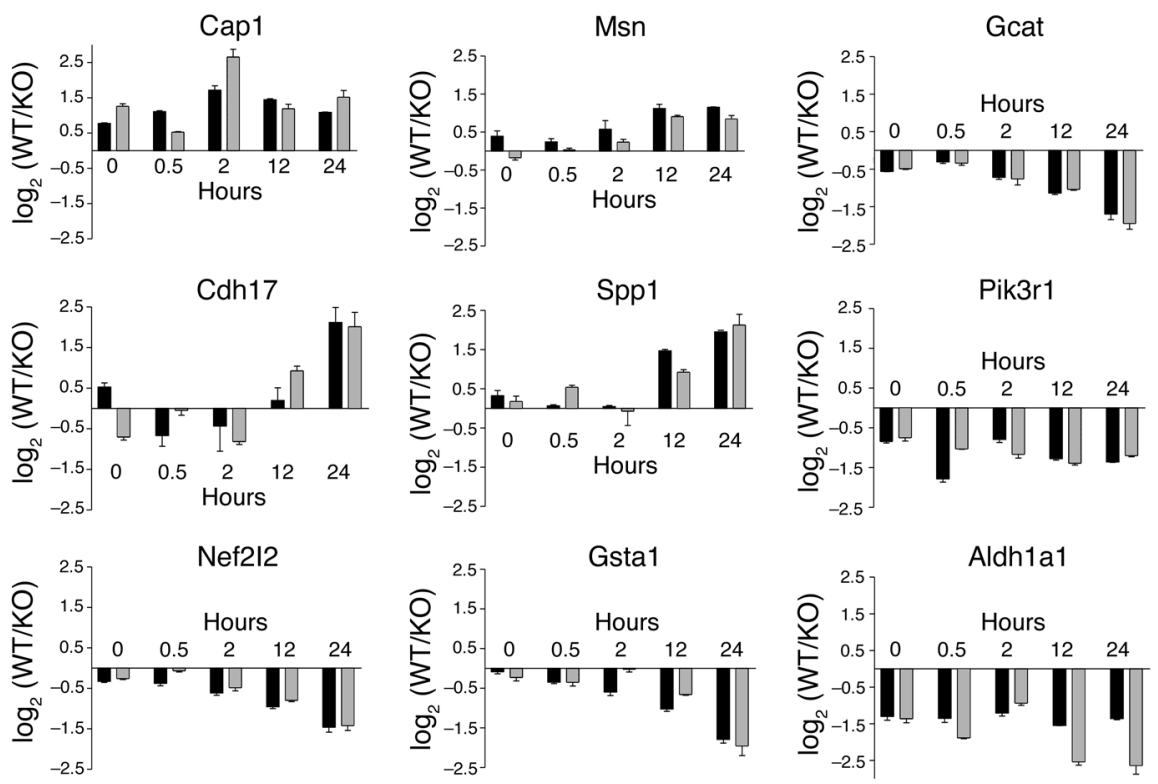

\section{Figure 3}

Comparison of gene expression patterns of selected Met-regulated genes from microarray and real-time PCR experiments. Gene expression levels in real-time PCR experiments were normalized to $\beta_{2}$-microglobulin expression, and the average expression ratios between WT control and Met KO hepatocytes were calculated from triplicate experiments at the different treatment points. Each bar represents the $\log _{2}$-transformed mean expression ratios \pm SEM.

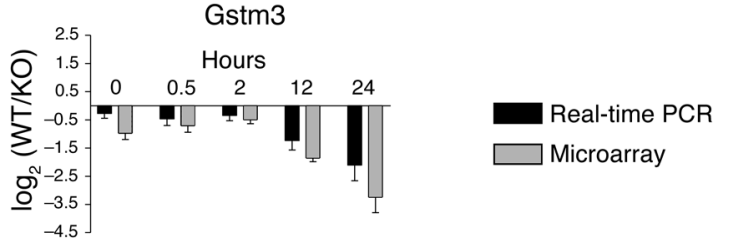

overlapped in the horizontal and vertical comparisons, indicating that the majority of the differentially expressed genes represented a specific response to HGF induction.

Expression differences observed with microarray profiling were verified by quantitative RT-PCR analysis. Good correlation with microarray data was found for all 10 randomly selected significant genes (Figure 3).

Functional analysis of target genes confirms the role of Met as an essential regulator of cell motility. In accordance with previous studies, we detected significant changes in the expression levels of known Met target genes, including Hmga1, Spp1 (21), Itgß1 (22), Egr1 (23), and Cldn2 (24). Consecutive functional analysis of the Met target genes allowed a more detailed insight into the cellular machinery associated with the Met-induced phenotype. A significant number of genes induced at 12 and 24 hours were involved in cell motility (Cxcl10, Capn2, Spp1, Fn1), angiogenesis (Vcam1, Anptl4, Ctgf, Neo1, Robo1), cell adhesion (Cldn2, Tjp3, Cdh17), and cytoskeletal organization (Hspa5, Arpc1b, Cap1, Nck2, Tpm2, Msn, Mid1, Vim, Dnm3, Tubb3, Tubb6, Krt2-8, Tuba1). Some of these significant genes, arranged by their postulated functions, are listed in Table 1 . We also observed an early induction of several transcription factors (Hmga1, Egr1, JunB, MafF) after HGF treatment. A number of these immediate early targets of the Met pathway could regulate the expression of other differentially expressed genes at the later treatment points. This type of multistep regulation is well documented in the case of the HGF-Egr1-fibronectin (Fn) sequence (25).

HGF treatment had an especially prominent effect on the expression of genes involved in actin cytoskeleton organization and lamellipodium formation. Thus, HGF significantly upregulated Arpc1b and Nck2, a member and an important activator, respectively, of the Arp2/3 complex, which is involved in the regulation of the actin polymerization, particularly at the leading edge of moving cells (26). Furthermore, genes such as the Ras-responsive adenylyl cyclase-associated protein (Cap1), a key regulator of actin and cofilin turnover (27), as well as moesin (Msn), which connects actin filaments to the cell membrane (28), were induced by HGF treatment. Similarly, upregulation of tubulin- $\alpha 1,-\beta 3$, and $-\beta 6$ demonstrated that microtubular elements are transcriptional targets of Met signaling. The peak expression of the cell motilityrelated genes occurred at 12 and 24 hours coincidently with the onset of HGF-induced scattering in hepatocyte cultures. Differential expression of genes involved in actin cytoskeleton and microtubular organization as well as cell adhesion was consistent with the phenotypic differences revealed by immunofluorescence staining of WT and KO hepatocytes with antibodies against F-actin, $\alpha$-tubulin, and vinculin after 24 hours of HGF treatment (Supplemental Figure 1, A-F; supplemental material available online with this article; doi:10.1172/JCI27236DS1).

We also found that osteopontin (Spp1), a secreted glycoprotein, was upregulated by HGF in primary hepatocytes, in agreement with published data (21). Previously, CD44v6, a surface receptor for osteopontin, was also identified as a Met target gene (23). Although CD44 was not differentially expressed in our model, we detected a concomitant induction of several integrin family members, including integrin- $\alpha V(\operatorname{Itg} \alpha V)$, integrin- $\alpha 3(\operatorname{Itg} \alpha 3)$, and integrin- $\beta 1(\operatorname{Itg} \beta 1)$ (29). Interestingly, $\alpha_{v} \beta_{3}$ integrin binding to osteopontin forms a complex that facilitates angiogenesis and tumor cell migration (30). Thus our data provide genetic evidence that transcriptional induction of genes controlling migratory and angiogenesis programs represents an essential part of Met signaling.

Expression profiling reveals a novel regulatory function of the Met pathway in oxidative stress response. Among the most striking observa- 
Table 1

Functional classification of selected HGF/Met target genes

\begin{tabular}{|c|c|c|c|c|c|c|}
\hline \multirow[t]{2}{*}{ Gene symbol } & \multirow[t]{2}{*}{ UniGene ID } & \multirow[t]{2}{*}{ Temporal regulation } & \multicolumn{2}{|c|}{ WT control vs. Met KO } & \multicolumn{2}{|c|}{ WT control vs. WT control } \\
\hline & & & Time point & Fold difference & Time point & Fold differenc \\
\hline \multicolumn{7}{|c|}{ Nuclear proteins } \\
\hline Ankrd1 & Mm.10279 & Persistent & $\mathrm{Oh}$ & 0.39 & $0.5-2 \mathrm{~h}$ & 0.59 \\
\hline Cebpa & Mm.349667 & Late down & $24 \mathrm{~h}$ & 0.57 & $0-24 \mathrm{~h}$ & 0.47 \\
\hline Chd1 & Mm.8137 & Early and late up & $12 \mathrm{~h}$ & 3.27 & $0-12 \mathrm{~h}$ & 1.62 \\
\hline Ctcf & Mm.269474 & Late up & $12 \mathrm{~h}$ & 2.10 & $2-12 \mathrm{~h}$ & 1.68 \\
\hline Egr1 & Mm.181959 & Early up & $2 \mathrm{~h}$ & 2.64 & $0-0.5 \mathrm{~h}$ & 1.97 \\
\hline Foxp1 & Mm.234965 & Late up & $12 \mathrm{~h}$ & 2.11 & $2-12 \mathrm{~h}$ & 2.39 \\
\hline Gsh2 & Mm.218752 & Persistent & $12 \mathrm{~h}$ & 0.54 & $0.5-2 \mathrm{~h}$ & 0.86 \\
\hline Hmga1 & Mm.4438 & Early and late up & $24 \mathrm{~h}$ & 3.28 & $2-12 \mathrm{~h}$ & 2.11 \\
\hline Kpnb1 & Mm.251013 & Late up & $12 \mathrm{~h}$ & 1.51 & $2-12 \mathrm{~h}$ & 2.19 \\
\hline MafF & Mm.86646 & Early up & $2 \mathrm{~h}$ & 3.36 & $0-2 \mathrm{~h}$ & 2.38 \\
\hline $\mathrm{NCl}$ & Mm.154378 & Early up & $2 \mathrm{~h}$ & 1.65 & $0.5-2 \mathrm{~h}$ & 2.22 \\
\hline $\mathrm{Nfe} 212^{\mathrm{A}}$ & Mm.1025 & Late down & $24 \mathrm{~h}$ & 0.13 & $2-12 \mathrm{~h}$ & 0.62 \\
\hline Nfyb & Mm.245998 & Late down & $24 \mathrm{~h}$ & 0.60 & $2-12 \mathrm{~h}$ & 0.57 \\
\hline \multicolumn{7}{|c|}{ Signal transduction } \\
\hline Acvr1 & Mm.689 & Late up & $12 \mathrm{~h}$ & 2.67 & $0-12 \mathrm{~h}$ & 3.09 \\
\hline Cai & Mm.2442 & Early and late up & $0.5 \mathrm{~h}$ & 4.51 & $2-12 \mathrm{~h}$ & 3.08 \\
\hline Clic1 & Mm.29524 & Early and late up & $12 \mathrm{~h}$ & 2.78 & $0-12 \mathrm{~h}$ & 2.13 \\
\hline Eif4a2 & Mm.260084 & Persistent & $2 \mathrm{~h}$ & 2.01 & $0.5-2 \mathrm{~h}$ & 1.69 \\
\hline Epha7 & Mm.257266 & Persistent & $12 \mathrm{~h}$ & 0.66 & $0-12 \mathrm{~h}$ & 0.62 \\
\hline GOs2 & Mm.3283 & Late up & $12 \mathrm{~h}$ & 3.12 & $2-12 \mathrm{~h}$ & 3.80 \\
\hline Gpc6 & Mm.234129 & Early and late down & $24 \mathrm{~h}$ & 0.44 & $2-12 \mathrm{~h}$ & 0.43 \\
\hline Hbegf & Mm.289681 & Early up & $0.5 \mathrm{~h}$ & 2.56 & $0-0.5 \mathrm{~h}$ & 2.29 \\
\hline$N g f b$ & Mm.1259 & Late up & $12 \mathrm{~h}$ & 2.71 & $2-12 \mathrm{~h}$ & 2.55 \\
\hline Pik3r1 & Mm.259333 & Persistent & $12 \mathrm{~h}$ & 0.38 & $2-12 \mathrm{~h}$ & 0.56 \\
\hline Ppp1r10 & Mm.29385 & Early up & $2 \mathrm{~h}$ & 1.58 & $0.5-2 \mathrm{~h}$ & 1.68 \\
\hline Pps & Mm.1458 & Late up & $24 \mathrm{~h}$ & 2.82 & $0-24 \mathrm{~h}$ & 2.04 \\
\hline Rab12 & Mm.248313 & Late up & $24 \mathrm{~h}$ & 2.48 & $0-24 \mathrm{~h}$ & 1.78 \\
\hline Rab19 & Mm.123866 & Early up & $0.5 \mathrm{~h}$ & 3.69 & $0-0.5 \mathrm{~h}$ & 3.34 \\
\hline Rrad & Mm.29467 & Early and late up & $12 \mathrm{~h}$ & 2.99 & $0-12 \mathrm{~h}$ & 2.42 \\
\hline Smurf2 & Mm.340955 & Late up & $12 \mathrm{~h}$ & 1.68 & $0-12 \mathrm{~h}$ & 1.83 \\
\hline \multicolumn{7}{|l|}{ Angiogenesis } \\
\hline Angpt/3 & Mm.28341 & Early and late down & $12 \mathrm{~h}$ & 0.47 & $2-12 \mathrm{~h}$ & 0.45 \\
\hline Angpt/4 & Mm.196189 & Early up & $0.5 \mathrm{~h}$ & 1.94 & $0-0.5 \mathrm{~h}$ & 1.82 \\
\hline Anxa2 & Mm.238343 & Late up & $12 \mathrm{~h}$ & 1.54 & $2-12 \mathrm{~h}$ & 2.35 \\
\hline Ctgf & Mm.1810 & Late up & $12 \mathrm{~h}$ & 2.93 & $0-12 \mathrm{~h}$ & 5.91 \\
\hline Neo1 & $\mathrm{Mm} .42249$ & Late up & $24 \mathrm{~h}$ & 2.70 & $0-24 \mathrm{~h}$ & 3.65 \\
\hline Robo1 & Mm.256956 & Early and late down & $24 \mathrm{~h}$ & 0.42 & $2-12 \mathrm{~h}$ & 0.58 \\
\hline Rtn4 & Mm.192580 & Late up & $12 \mathrm{~h}$ & 1.65 & $2-12 \mathrm{~h}$ & 1.92 \\
\hline \multirow{2}{*}{\multicolumn{7}{|c|}{ Apoptosis regulation }} \\
\hline & & & & & & \\
\hline Bak1 & Mm.2443 & Late up & $12 \mathrm{~h}$ & 1.73 & $2-12 \mathrm{~h}$ & 1.37 \\
\hline Bnip3 & Mm.2159 & Persistent & $12 \mathrm{~h}$ & 0.63 & $2-12 \mathrm{~h}$ & 0.69 \\
\hline Fas & Mm.1626 & Early and late down & $2 \mathrm{~h}$ & 0.45 & $2-12 \mathrm{~h}$ & 0.38 \\
\hline Moap1 & Mm.291222 & $\begin{array}{l}\text { Early up } \\
\text { Latin }\end{array}$ & $24 \mathrm{~h}$ & 0.61 & $0-24 \mathrm{~h}$ & 0.51 \\
\hline Pea15 & $\mathrm{Mm} .544$ & Early and late up & $24 \mathrm{~h}$ & 2.62 & $0-24 \mathrm{~h}$ & 1.93 \\
\hline \multirow{2}{*}{\multicolumn{7}{|c|}{ Cell adhesion }} \\
\hline & & & & & & \\
\hline Cdh17 & Mm.33402 & Late up & $24 \mathrm{~h}$ & 3.98 & $0-24 \mathrm{~h}$ & 6.90 \\
\hline Cldn2 & Mm.117068 & Late down & $24 \mathrm{~h}$ & 0.48 & $0-24 \mathrm{~h}$ & 0.56 \\
\hline Tjp3 & Mm.27984 & Persistent & $2 \mathrm{~h}$ & 0.45 & $0-2 \mathrm{~h}$ & 0.77 \\
\hline Cytoskeletal or & ion and cell mo & & & & & \\
\hline $\mathrm{CxCl} 2$ & Mm.4979 & Persistent & $0.5 \mathrm{~h}$ & 1.87 & $0-0.5 \mathrm{~h}$ & 0.99 \\
\hline Hspa5 & Mm.330160 & Early and late up & $0.5 \mathrm{~h}$ & 3.97 & $2-12 \mathrm{~h}$ & 2.63 \\
\hline Mmp7 & Mm.4825 & Early and late up & $0.5 \mathrm{~h}$ & 2.06 & $2-12 \mathrm{~h}$ & 2.14 \\
\hline Tpm2 & Mm.646 & Persistent & $0.5 \mathrm{~h}$ & 0.28 & $0.5-2 \mathrm{~h}$ & 0.78 \\
\hline Cap1 & Mm.8687 & Early and late up & $2 \mathrm{~h}$ & 6.30 & $2-12 \mathrm{~h}$ & 1.75 \\
\hline Cxc/10 & Mm.877 & Early up & $2 \mathrm{~h}$ & 1.86 & $0-2 \mathrm{~h}$ & 1.39 \\
\hline Mid1 & Mm.34441 & Early up & $2 \mathrm{~h}$ & 2.28 & $0.5-2 \mathrm{~h}$ & 2.46 \\
\hline Vim & $\mathrm{Mm} .268000$ & Early down & $2 \mathrm{~h}$ & 0.40 & $0-0.5 \mathrm{~h}$ & 0.78 \\
\hline Arpc1b & Mm.30010 & Late up & $12 \mathrm{~h}$ & 1.64 & $2-12 \mathrm{~h}$ & 1.73 \\
\hline Capn2 & Mm.19306 & Late up & $12 \mathrm{~h}$ & 1.69 & $2-12 \mathrm{~h}$ & 2.23 \\
\hline Dnm3 & Mm.29567 & Late up & $12 \mathrm{~h}$ & 1.78 & $2-12 \mathrm{~h}$ & 1.70 \\
\hline Msn & Mm.138876 & Late up & $12 \mathrm{~h}$ & 1.88 & $0-24 \mathrm{~h}$ & 2.73 \\
\hline Tubb3 & Mm.40068 & Early and late up & $12 \mathrm{~h}$ & 2.07 & $0-12 \mathrm{~h}$ & 1.74 \\
\hline Tubb6 & Mm.181860 & Late up & $12 \mathrm{~h}$ & 2.05 & $0-12 \mathrm{~h}$ & 1.80 \\
\hline Krt2-8 & Mm.358618 & Late up & $24 \mathrm{~h}$ & 1.55 & $0-24 \mathrm{~h}$ & 1.66 \\
\hline Tuba1 & Mm.371591 & Late up & $24 \mathrm{~h}$ & 2.41 & $0-24 \mathrm{~h}$ & 6.13 \\
\hline Spp1 & $\mathrm{Mm} .288474$ & Late up & $24 \mathrm{~h}$ & 4.38 & $0-24 \mathrm{~h}$ & 2.34 \\
\hline
\end{tabular}




\begin{tabular}{|c|c|c|c|c|c|c|}
\hline \multicolumn{7}{|c|}{ Integrin-mediated signaling } \\
\hline Itgav & Mm.227 & Late up & $12 \mathrm{~h}$ & 1.52 & $2-12 \mathrm{~h}$ & 2.38 \\
\hline Itga3 & Mm.57035 & Late up & $12 \mathrm{~h}$ & 1.57 & $0-24 \mathrm{~h}$ & 2.21 \\
\hline Adam24 & Mm.67403 & Early and late up & $12 \mathrm{~h}$ & 2.79 & $2-12 \mathrm{~h}$ & 1.70 \\
\hline Fn1 & Mm.193099 & Late up & $24 \mathrm{~h}$ & 1.52 & $0-24 \mathrm{~h}$ & 2.91 \\
\hline $\operatorname{ltg} 1$ & Mm.263396 & Late up & $24 \mathrm{~h}$ & 1.54 & $2-12 \mathrm{~h}$ & 1.71 \\
\hline \multicolumn{7}{|c|}{ Stress response } \\
\hline Adh1 & Mm.2409 & Persistent & $24 \mathrm{~h}$ & 0.13 & $2-12 \mathrm{~h}$ & 0.49 \\
\hline Aldh1a1A & Mm.250866 & Persistent & $24 \mathrm{~h}$ & 0.16 & $2-12 \mathrm{~h}$ & 0.69 \\
\hline Aldh1a7 & Mm.14609 & Persistent & $24 \mathrm{~h}$ & 0.21 & $2-12 \mathrm{~h}$ & 0.75 \\
\hline Ephx1A & Mm.9075 & Late down & $24 \mathrm{~h}$ & 0.11 & $0-24 \mathrm{~h}$ & 0.39 \\
\hline Gclc ${ }^{A}$ & Mm.89888 & Late down & $12 \mathrm{~h}$ & 0.48 & $0-12 \mathrm{~h}$ & 0.58 \\
\hline Gsta1A & Mm.335309 & Late down & $24 \mathrm{~h}$ & 0.27 & $0-24 \mathrm{~h}$ & 0.45 \\
\hline Gsta3 ${ }^{A}$ & Mm.14719 & Early and late down & $24 \mathrm{~h}$ & 0.18 & $0-24 \mathrm{~h}$ & 0.30 \\
\hline Gstm2A & Mm.272792 & Persistent & $24 \mathrm{~h}$ & 0.19 & $0-24 \mathrm{~h}$ & 0.39 \\
\hline Gstm $3^{A}$ & Mm.347436 & Persistent & $24 \mathrm{~h}$ & 0.22 & $0-24 \mathrm{~h}$ & 0.44 \\
\hline Gstm6 $6^{A}$ & Mm.347437 & Early and late down & $24 \mathrm{~h}$ & 0.30 & $0-24 \mathrm{~h}$ & 0.34 \\
\hline Gstz1A & Mm.358602 & Early and late down & $24 \mathrm{~h}$ & 0.51 & $2-12 \mathrm{~h}$ & 0.50 \\
\hline Mgst1 & Mm.14796 & Late down & $24 \mathrm{~h}$ & 0.40 & $0-24 \mathrm{~h}$ & 0.40 \\
\hline Orm2 & Mm.14173 & Early down & $2 \mathrm{~h}$ & 0.58 & $0.5-2 \mathrm{~h}$ & 0.40 \\
\hline Saa4 & Mm.3489 & Late down & $24 \mathrm{~h}$ & 0.55 & $0-24 \mathrm{~h}$ & 0.47 \\
\hline \multicolumn{7}{|c|}{ Lipid metabolism } \\
\hline Acox 1 & Mm.356689 & Persistent & $24 \mathrm{~h}$ & 0.53 & $0-12 \mathrm{~h}$ & 0.67 \\
\hline Ass1 & Mm.3217 & Persistent & $0.5 \mathrm{~h}$ & 0.55 & $2-12 \mathrm{~h}$ & 0.62 \\
\hline Bucs1 & Mm.33731 & Early and late down & $12 \mathrm{~h}$ & 0.50 & $2-12 \mathrm{~h}$ & 0.19 \\
\hline Crot & Mm.28197 & Early and late down & $24 \mathrm{~h}$ & 0.39 & $0-24 \mathrm{~h}$ & 0.62 \\
\hline Cyp4a10 & Mm.10742 & Early and late down & $12 \mathrm{~h}$ & 0.22 & $2-12 \mathrm{~h}$ & 0.11 \\
\hline Cур4a14 & Mm.250901 & Early and late down & $0.5 \mathrm{~h}$ & 0.47 & $2-12 \mathrm{~h}$ & 0.34 \\
\hline Dgat2 & Mm.180189 & Early up & $0.5 \mathrm{~h}$ & 1.60 & $0-0.5 \mathrm{~h}$ & 1.43 \\
\hline Ech1 & Mm.291776 & Persistent & $24 \mathrm{~h}$ & 0.56 & $2-12 \mathrm{~h}$ & 0.58 \\
\hline Fabp1 & Mm.22126 & Late down & $24 \mathrm{~h}$ & 0.23 & $2-12 \mathrm{~h}$ & 0.04 \\
\hline Fasn & Mm.236443 & Early and late down & $0.5 \mathrm{~h}$ & 0.32 & $2-12 \mathrm{~h}$ & 0.23 \\
\hline Gcdh & Mm.2475 & Persistent & $12 \mathrm{~h}$ & 0.50 & $2-12 \mathrm{~h}$ & 0.48 \\
\hline Gckr & Mm.100043 & Early and late down & $24 \mathrm{~h}$ & 0.50 & $0-24 \mathrm{~h}$ & 0.28 \\
\hline Gldc & Mm.274852 & Late up & $12 \mathrm{~h}$ & 1.64 & $2-12 \mathrm{~h}$ & 2.29 \\
\hline Glyat & Mm.39974 & Early and late down & $24 \mathrm{~h}$ & 0.23 & $12-24 \mathrm{~h}$ & 0.35 \\
\hline Gpam & Mm.210196 & Persistent & $24 \mathrm{~h}$ & 0.51 & $12-24 \mathrm{~h}$ & 0.69 \\
\hline Lip1 & Mm.157545 & Early and late down & $2 \mathrm{~h}$ & 0.45 & $0.5-2 \mathrm{~h}$ & 0.54 \\
\hline Lipc & Mm.362 & Persistent & $12 \mathrm{~h}$ & 0.53 & $0-12 \mathrm{~h}$ & 0.64 \\
\hline MGC29978 & Mm.224885 & Early and late down & $24 \mathrm{~h}$ & 0.37 & $2-12 \mathrm{~h}$ & 0.38 \\
\hline Mrp/38 & Mm.29974 & Persistent & $24 \mathrm{~h}$ & 2.05 & $0-24 \mathrm{~h}$ & 1.41 \\
\hline Mscp & Mm.293635 & Late up & $12 \mathrm{~h}$ & 2.26 & $2-12 \mathrm{~h}$ & 1.78 \\
\hline Otc & Mm.2611 & Persistent & $12 \mathrm{~h}$ & 0.52 & $2-12 \mathrm{~h}$ & 0.31 \\
\hline Pklr & Mm.8359 & Early and late down & $2 \mathrm{~h}$ & 0.45 & $12-24 \mathrm{~h}$ & 0.49 \\
\hline Scp2 & Mm.209568 & Late down & $24 \mathrm{~h}$ & 0.25 & $0-24 \mathrm{~h}$ & 0.21 \\
\hline
\end{tabular}

APreviously reported Nfe2l2 target genes.

tions was a profound misregulation of genes involved in antioxidative stress response and glutathione metabolism in $\mathrm{Met}$ KO hepatocytes. Notably, the transcription factor nuclear factor (erythroid-derived 2)-like 2 ( $\mathrm{Nfe} 2 \mathrm{l2}$ ), as well as numerous oxidative stress response genes (Aldh1a1, Aldh1a7, Adb1, Ephx1, Ephx2), glutathione-S-transferase isotypes (Gsta1, Gsta3, Gstm6, Mgst1, Gstm2, Gstm3), and glutamate-cysteine ligase (Gclc), a regulator of glutathione metabolism (31), showed significant overexpression in the Met KO hepatocytes. The majority of these genes are well-documented targets of the basic helix-loop-helix transcription factor $\mathrm{Nfe} 2 \mathrm{l} 2$ (32), a key regulator of a detoxifying pathway activated by increased oxidative or xenobiotic stress in cells. Consistent with the microarray data, increased nuclear levels of $\mathrm{Nfe} 212$ protein were detected both in cultured hepatocytes and in intact livers from $\mathrm{Met} \mathrm{KO}$ mice (our unpublished observations). In contrast, nuclear dimerization partners and possible antagonists of $\mathrm{Nfe} 2 \mathrm{l} 2$, the nuclear factors MafF and MafK (33), were more abundant in the control hepatocytes. Upregulation of the antioxidant genes may reflect the altered redox homeostasis of the KO cells. This was also evidenced by decreased oxidized/reduced glutathione ratios (Supplemental Figure 1G) as well as by increased staining with the oxidation-sensitive probe $2^{\prime}, 7^{\prime}$-dichlorofluorescin (Supplemental Figure $1 \mathrm{H}$ ) in the Met KO hepatocytes.

Comparative functional genomic analysis identifies a subgroup of buman HCCs with a prominent Met gene expression signature. Based on the previous reports $(5,34)$, we hypothesized that a considerable part of the Met gene expression signature may be conserved between mouse and human hepatocytes. Therefore, the expression signature generated using mouse hepatocytes could be applied to identify human HCCs with a prominent activation of the Met pathway. To test this hypothesis, we directly compared the expression profiles of the Met-regulated genes in mouse hepatocytes with those from 242 human HCC samples. Based on a list of curated homologous UniGene clusters (http://ncbi. nlm.nih.gov/UniGene/), we collected available human orthologs of the 730 Met-dependent mouse genes in 2 human HCC data sets. The first set, composed of 139 HCC samples $(35,36)$, has been previously analyzed in our laboratory (LEC [Laboratory of Experimental Carcinogenesis, National Cancer Institute] set), while the second set, containing expression profiles of 103 HCCs and 7 liver metastases, was obtained from the Stanford University microarray database (37). 
A
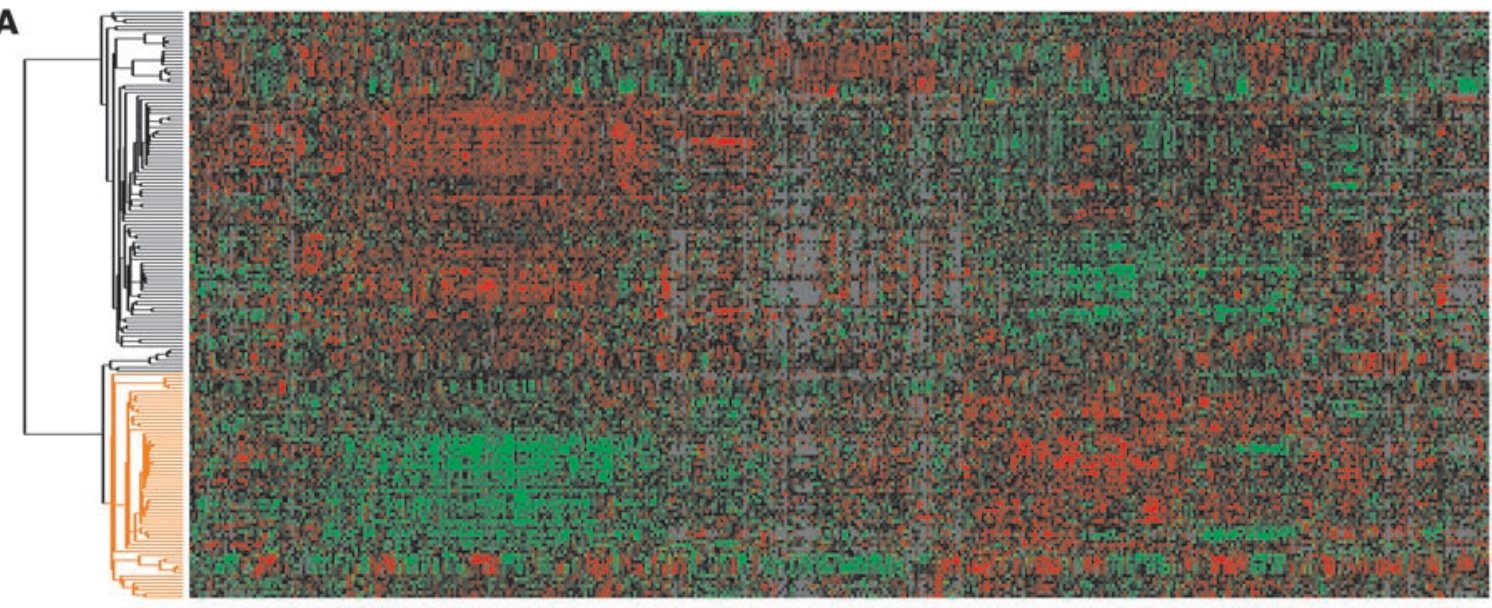

$-1.5$

0

1.5

B

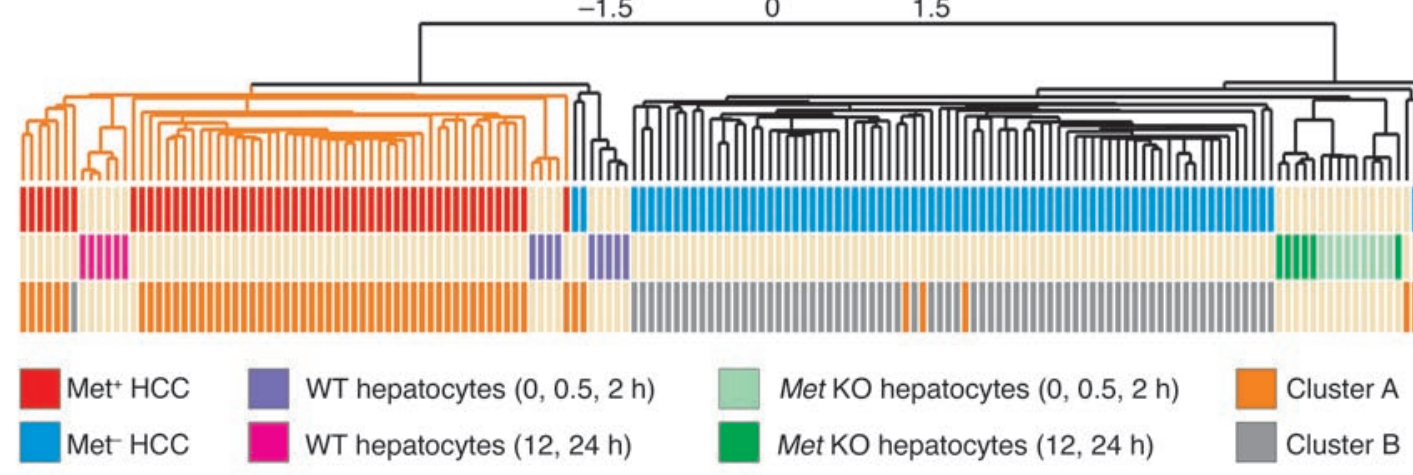

\section{Figure 4}

Expression profiles of the Met-regulated genes in HCCs from the LEC data set. (A) Hierarchical cluster analysis of mouse hepatocyte samples and $139 \mathrm{HCC}$ from the LEC data set. Clustering was performed with 440 common orthologous genes that showed HGF/Met-regulated expression pattern in mouse hepatocytes. Normalized $\log _{2}$-transformed expression ratios are presented in a matrix where columns and rows represent individual genes and samples, respectively. (B) Dendrogram of cluster analysis indicates the presence of an HCC subset (Met+ group) in which the expression pattern of Met-regulated genes is similar to that in the HGF-treated WT hepatocyte samples. HCC samples in the Met- group and Met KO hepatocytes do not share the same gene expression pattern of Met activation. The figure also shows distribution of HCC samples between the previously described (37) worse-prognosis (cluster A) and better-prognosis (cluster B) tumor groups.

Expression values were standardized for each gene by adjustment of SD to 1 and mean to 0 separately across all samples independently in the 3 different platforms as previously described (38). Next, we constructed 2 composite mouse-human data sets. One contained the expression profiles of 440 common genes from the LEC HCCs and from the mouse hepatocyte samples, whereas the second data set included 303 orthologous genes from the Stanford HCC tumors and from the mouse samples. Cluster analysis identified 2 distinctive clusters in both independent mouse-human data sets (Figures 4A and 5A), which divided HCC samples into 2 subgroups based on the presence $\left(\mathrm{Met}^{+}\right)$or absence $\left(\mathrm{Met}^{-}\right)$of Met gene expression signature. Tumors in the $\mathrm{Met}^{+}$group showed an expression pattern highly similar to that of HGF-induced control hepatocytes. Strikingly, all 7 extrahepatic liver metastases included in the Stanford data set also exhibited a clear Met activation pattern (Figures 4B and $5 \mathrm{~B}$ ). These results indicate that the Met gene expression signature identified in the mouse primary hepatocytes may successfully discriminate a significant subset of human HCC.

Prevalence of Met-regulated gene expression signature is associated with aggressive phenotype in human HCC. Kaplan-Meier plots and log-rank survival statistics showed that patients with tumors from the $\mathrm{Met}^{+}$ expression subgroup had a significantly shortened mean survival time $(35.1 \pm 7.15$ months) compared with other HCC patients (70.3 \pm 9.67 months) (Figure 6A). Hierarchical cluster analysis also revealed significant overlap between the $\mathrm{Met}^{+}$group and the previously identified (35) bad-prognosis HCC group (cluster A) as shown in Figure 4B. Distribution of other clinicopathological variables among the $\mathrm{Met}^{+}$and $\mathrm{Met}^{-}$clusters is summarized in Table 2 .

Since Met signaling has long been regarded as a promoter of tumor invasion and angiogenesis, we determined the vascular invasion status in HCCs available for histological analysis. As expected, the vascular invasion rate was significantly higher in the HCCs with prominent Met expression signature $\left(\chi^{2}=4.01\right.$, $P \leq 0.05)$ than in the rest of the tumors (Figure $6 \mathrm{~B}$ ). Previous studies found a good correlation between the expression levels of HGF or Met receptor and microvessel density (MVD) in various human carcinomas $(39,40)$. Indeed, when MVD was assessed by CD34 immunohistochemistry in the representative HCC samples from each group, the results showed a significant correlation between the presence of Met signature and increased MVD. 
A
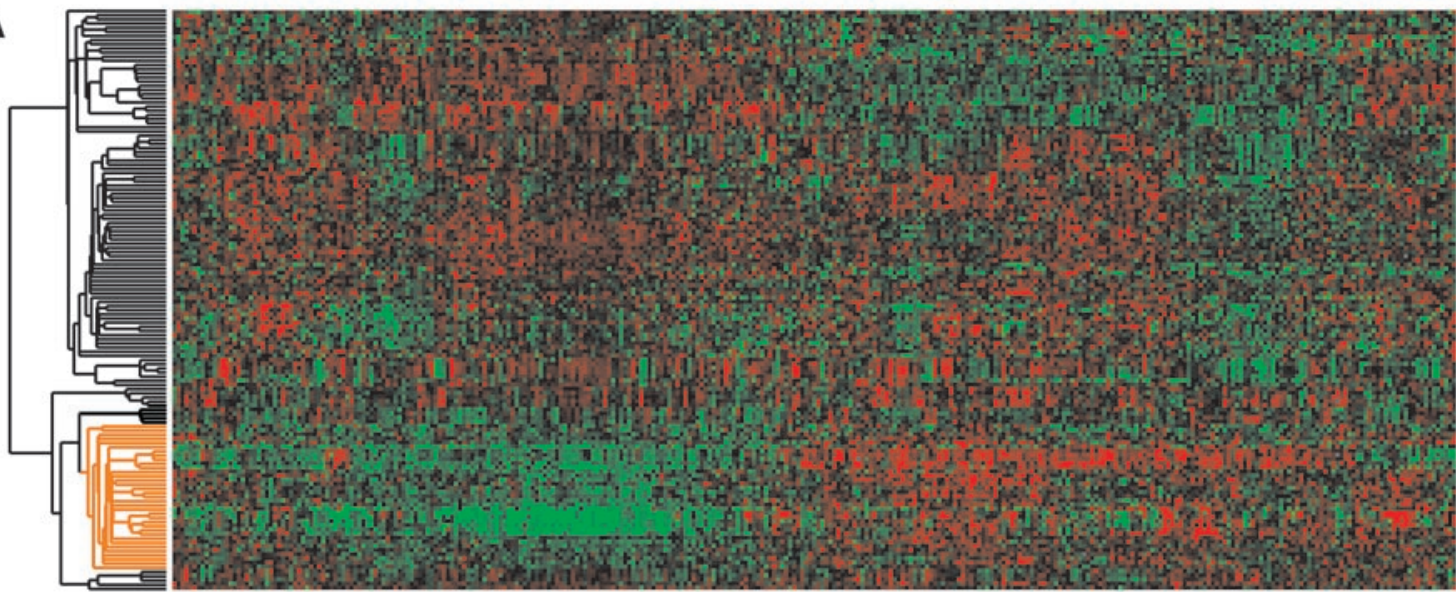

B

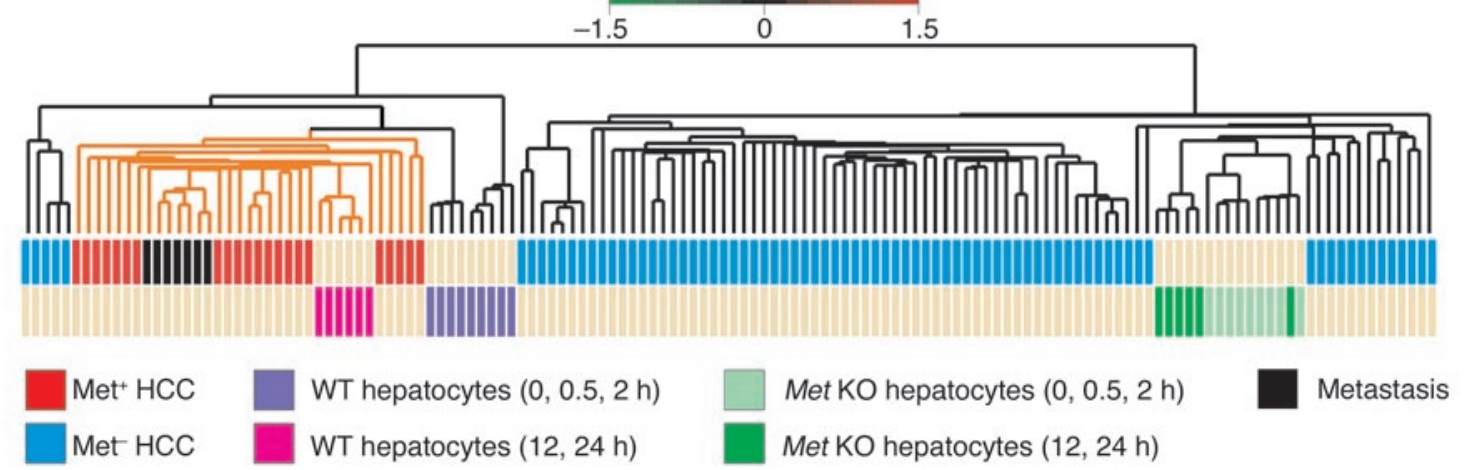

Figure 5

Expression profiles of the Met-regulated genes in HCCs from the Stanford data set. (A) Hierarchical cluster analysis of mouse hepatocyte samples together with $103 \mathrm{HCC}$ and 7 liver metastases from the Stanford data set. Clustering was performed with 303 common orthologous genes that showed HGF/Met-regulated expression pattern in mouse hepatocytes. Normalized $\log _{2}$-transformed expression ratios are presented in a matrix where columns and rows represent individual genes and samples, respectively. (B) Dendrogram of cluster analysis shows that several $\mathrm{HCC}$ samples and all metastatic tumors (Met ${ }^{+}$group) share a similar expression pattern with the HGF-treated control hepatocytes (WT). HCC samples in the Met group and Met KO hepatocytes do not share the same gene expression pattern of Met activation.

Accordingly, the average $\mathrm{OD}$ of $\mathrm{CD} 34^{+}$vascular features was significantly higher $(P<0.001)$ in the $\operatorname{Met}^{+}(90.78 \pm 6.71)$ than in the $\mathrm{Met}^{-}(44.55 \pm 6.16)$ HCC subgroup (Figure 6, C-E).

Notably, in the LEC data set, average expression level of the Met was not significantly different between the $\mathrm{Met}^{-}$and $\mathrm{Met}^{+}$clusters as detected by either microarray analysis or immunohistochemistry (data not shown). However, at least 2-fold upregulation of the Met receptor was found more frequently in the $\mathrm{Met}^{+}$tumors $(5 / 54)$ compared with the $\mathrm{Met}^{-}$group (2/85) in the LEC set. These data overlap well with the expression profile-based classification and suggest that, in some HCCs, overexpression of the Met receptor is the driving force behind the Met-dependent expression signature.

The Met expression signature predicts survival of HCC patients. To test the predictive value of the Met expression signature regarding prognosis of HCC patients, the expression patterns of the human homologs of the mouse Met-regulated genes were used to construct a classifier with 6 different supervised prediction algorithms, including the compound covariate predictor (CCP), nearest neighbors 1 and 3 (NN1 and NN3), nearest centroid (NC), support vector machine (SVM), and linear discriminator analysis (LDA) methods. Since survival data were only available for the patients from the LEC group, we randomly divided these samples into a training set
(60 samples) and a validation set (79 samples). Next, we selected the common target genes with the matching expression pattern between tumors displaying the high and low Met gene expression signature in the primary hepatocytes and in the training set. Using these genes and all 6 algorithms, classifiers were built according to a leave-one-out cross-validation (LOOCV) strategy. The optimal classifier producing the highest correct classification rate in the training set contained 111 genes. When the classifier was applied to the validation set, all 6 algorithms could identify the subgroups of $\mathrm{Met}^{+}$tumors. Moreover, membership of the $\mathrm{Met}^{+}$group showed little fluctuation using different statistical methods (Table 3). Kaplan-Meier survival curves and results of the log-rank tests with all predictors showed that HCC patients with tumors harboring prominent Met gene expression signature have a worse survival rate compared with other patients (Figure 7, A-E). We also applied the prediction algorithms to the Stanford arrays, using the same LEC training set and only genes that were represented in both platforms. In the Stanford data set, the prediction rate of the metastatic liver lesions was $100 \%$ with 5 of 6 algorithms.

Beyond predicting the disease outcome in HCC patients, the classifier genes may also represent the most conserved cross-species part of prominent HGF/Met-regulated expression signature that 

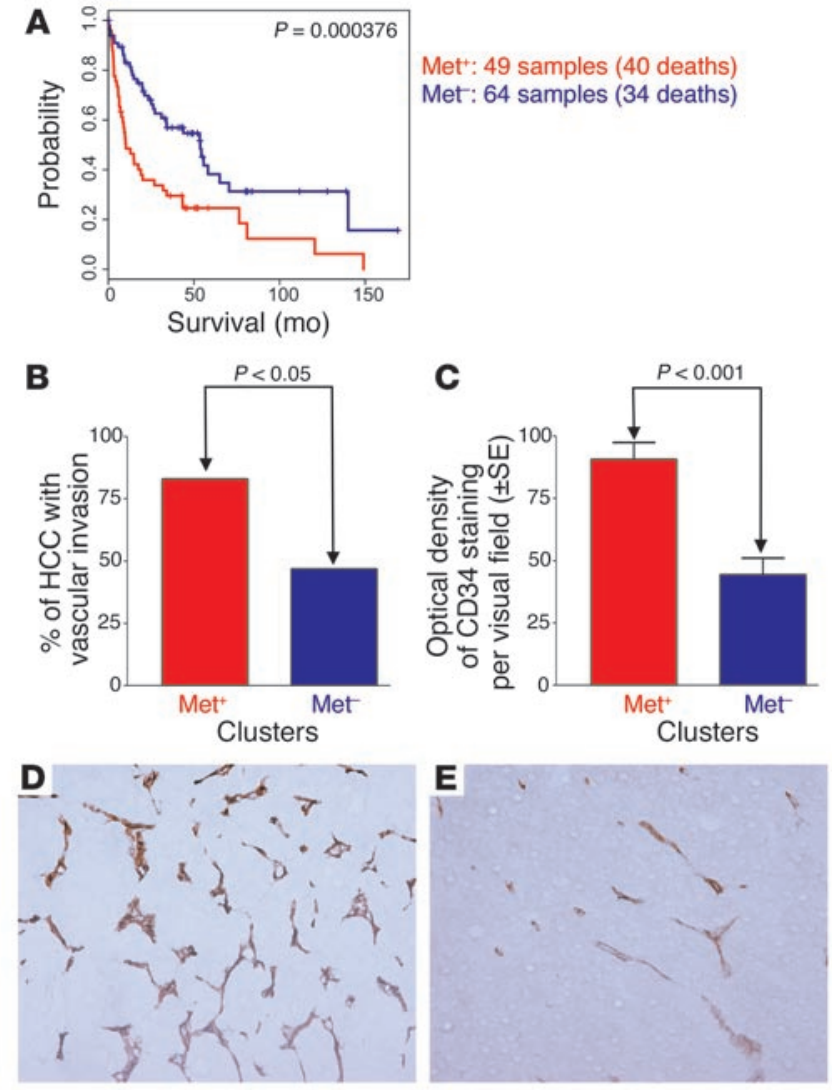

plays a critical role in the Met-induced cellular transformation. Several of these genes either were previously defined as important contributors to metastasis formation, including HIG2 (41), EPHA2 (42), MAPK3 (43), P85 $\alpha$ (44), ITG $\alpha V$ (29), and ITG $\beta 1$ (29), or could be related to cell motility and invasiveness by their postulated functions (CAP1, ARPC1B, NCK2) (Table 4) $(26,27,45)$.

\section{Discussion}

In the current study we used global gene expression profiling to identify the Met-regulated genes in primary mouse hepatocytes. Analysis of microarray data identified several new Met target genes. Some of these genes indicate a novel role for Met in the regulation of hepatocyte homeostasis. Furthermore, comparison of the Met-dependent gene expression signature between mouse hepatocytes and human HCC samples revealed the presence of a clinically significant subgroup of HCC patients with a pronounced Met gene expression signature.

Although many etiological risk factors leading to HCC development (HBV and HCV hepatitis or alcoholic liver disease) are well documented (46), the molecular events of HCC pathogenesis are still not clearly understood. Application of high-throughput techniques including expression microarrays could significantly improve our knowledge in this field. Indeed, recent studies successfully identified the differentially expressed gene sets associated with phenotypic markers or clinicopathological conditions such as viral etiology (47), tumor recurrence (48), and intrahepatic metastases (49) in HCC samples. Furthermore, the use of expression profiling made it possible to divide the HCC patients into subgroups with a significantly different disease outcome and sur-

\section{Figure 6}

Association between the different clinicopathological variables and the $\mathrm{Met}^{+}$and Met- HCC subsets defined by hierarchical cluster analysis of the LEC samples. Kaplan-Meier plot (A) and log-rank statistics demonstrate the difference in the overall survival between $\mathrm{HCC}$ patients from the $\mathrm{Met}^{+}$and from the Met groups. (B and C) Bar graphs represent vascular invasion rate (B) and average MVD (C) in $\mathrm{HCC}$ samples from $\mathrm{Met}^{+}$ and Met sets. MVD was determined by quantitative analysis of CD34+ vascular features. (D and E) Microscope images show CD34 staining of endothelial cells in representative samples from $\mathrm{Met}^{+}(\mathrm{D})$ and $\mathrm{Met}^{-}(\mathrm{E})$ tumor sets. Pictures were taken with $\times 200$ original magnification.

vival rate (35). However, the complexity of the expression profiles in the human tumors often prevents the identification of primary regulatory events. To overcome this limitation, we used a genetically modified mouse model and a functional genomic approach to identify a subgroup of HCCs characterized by a pronounced Met gene expression signature.

Multiple findings support the prominent clinical significance of the HCC classification based on the presence or absence of the

Table 2

Clinicopathological variables in the LEC HCC set

\begin{tabular}{|c|c|c|c|}
\hline Clinicopathological variable & $\begin{array}{l}\text { Met }^{+} \\
\text {cluster }\end{array}$ & $\begin{array}{l}\text { Met- } \\
\text { cluster }\end{array}$ & Total \\
\hline \multicolumn{4}{|l|}{ Sex } \\
\hline Male & 43 & 59 & 102 \\
\hline Female & 12 & 25 & 37 \\
\hline \multicolumn{4}{|l|}{ Age } \\
\hline Mean (yr) & 52.7 & 58.6 & 55.6 \\
\hline SD & 12.5 & 13.9 & 13.2 \\
\hline \multicolumn{4}{|l|}{ Liver cirrhosis } \\
\hline+ & 30 & 39 & 69 \\
\hline- & 24 & 46 & 70 \\
\hline \multicolumn{4}{|l|}{ Etiology } \\
\hline HBV hepatitis & 34 & 22 & 56 \\
\hline HCV hepatitis & 4 & 10 & 14 \\
\hline Alcoholic liver disease & 3 & 13 & 16 \\
\hline HBV + HCV hepatitis & 1 & 3 & 4 \\
\hline Alcohol + HBV & 0 & 1 & 1 \\
\hline Alcohol + HCV & 0 & 3 & 3 \\
\hline Nonalcoholic steatohepatitis & 0 & 2 & 2 \\
\hline Autoimmune hepatitis & 1 & 1 & 2 \\
\hline Hereditary hemochromatosis & 0 & 3 & 3 \\
\hline$\alpha_{1}-$ Antitrypsin deficiency & 0 & 1 & 1 \\
\hline Primary biliary cirrhosis & 0 & 1 & 1 \\
\hline Wilson disease & 1 & 0 & 1 \\
\hline Unknown & 11 & 24 & 35 \\
\hline \multicolumn{4}{|l|}{ Tumor size } \\
\hline$>5 \mathrm{~cm}$ & 33 & 34 & 67 \\
\hline$<5 \mathrm{~cm}$ & 15 & 26 & 41 \\
\hline \multicolumn{4}{|l|}{ AFP level } \\
\hline$>300 \mathrm{U}$ & 27 & 23 & 50 \\
\hline$<300 \mathrm{U}$ & 17 & 37 & 54 \\
\hline \multicolumn{4}{|l|}{ Edmondson grade } \\
\hline Grade I & 0 & 2 & 2 \\
\hline Grade II & 13 & 44 & 57 \\
\hline Grade III & 39 & 35 & 74 \\
\hline Grade IV & 3 & 3 & 6 \\
\hline
\end{tabular}

AFP, $\alpha$-phetoprotein. 
Table 3

Summary of the class prediction results

\begin{tabular}{|c|c|c|c|c|c|c|c|c|c|c|c|c|}
\hline \multirow[b]{2}{*}{ Predicted subclass } & \multicolumn{2}{|c|}{ ССР } & \multicolumn{2}{|c|}{ NN1 } & \multicolumn{2}{|c|}{ NN3 } & \multicolumn{2}{|c|}{ NC } & \multicolumn{2}{|c|}{ SVM } & \multicolumn{2}{|c|}{ LDA } \\
\hline & Met $^{+}$ & Met- $^{-}$ & Met $^{+}$ & Met- & $\mathrm{Met}^{+}$ & Met- $^{-}$ & Met $^{+}$ & Met- & Met $^{+}$ & Met- & Met $^{+}$ & Met $^{-}$ \\
\hline \multicolumn{12}{|l|}{ LEC data set } & \\
\hline Cluster $\operatorname{Met}^{+}(n=30)$ & 27 & 3 & 27 & 3 & 27 & 3 & 27 & 3 & 29 & 1 & 27 & 3 \\
\hline Cluster $\operatorname{Met}^{-}(n=30)$ & 2 & 28 & 1 & 29 & 1 & 29 & 2 & 28 & 2 & 28 & 2 & 29 \\
\hline $\begin{array}{l}\text { Correctly classified (\%) } \\
\text { Validation set }\end{array}$ & \multicolumn{2}{|c|}{92} & \multicolumn{2}{|c|}{93} & \multicolumn{2}{|c|}{93} & \multicolumn{2}{|c|}{92} & \multicolumn{2}{|c|}{95} & 92 & \\
\hline Cluster $\operatorname{Met}^{+}(n=28)$ & 23 & 5 & 23 & 5 & 24 & 4 & 22 & 6 & 24 & 4 & 23 & 5 \\
\hline Cluster $\operatorname{Met}^{-}(n=51)$ & 1 & 50 & 1 & 50 & 0 & 51 & 1 & 50 & 2 & 49 & 1 & 50 \\
\hline Correctly classified (\%) & \multicolumn{2}{|c|}{92} & \multicolumn{2}{|c|}{92} & \multicolumn{2}{|c|}{95} & \multicolumn{2}{|c|}{91} & \multicolumn{2}{|c|}{92} & \multicolumn{2}{|c|}{92} \\
\hline \multicolumn{13}{|l|}{ Stanford data set } \\
\hline Cluster $\mathrm{Met}^{+}(n=22)$ & 21 & 1 & 11 & 10 & 9 & 13 & 21 & 1 & 15 & 7 & 21 & 1 \\
\hline Cluster Met- $^{-}(n=81)$ & 11 & 70 & 8 & 73 & 10 & 71 & 12 & 69 & 11 & 70 & 11 & 70 \\
\hline $\begin{array}{l}\text { Correctly classified (\%) } \\
\text { Metastasis }\end{array}$ & \multicolumn{2}{|c|}{88} & \multicolumn{2}{|c|}{82} & \multicolumn{2}{|c|}{78} & \multicolumn{2}{|c|}{87} & \multicolumn{2}{|c|}{83} & \multicolumn{2}{|c|}{88} \\
\hline Cluster $\operatorname{Met}^{+}(n=7)$ & 7 & 0 & 7 & 0 & 7 & 0 & 7 & 0 & 6 & 1 & 7 & 0 \\
\hline Cluster Met- $(n=0)$ & 0 & 0 & 0 & 0 & 0 & 0 & 0 & 0 & 0 & 0 & 0 & 0 \\
\hline $\begin{array}{l}\text { Correctly classified (\%) } \\
\text { Significance of LOOCV }\end{array}$ & \multicolumn{2}{|c|}{100} & \multicolumn{2}{|c|}{100} & \multicolumn{2}{|c|}{100} & \multicolumn{2}{|c|}{100} & \multicolumn{2}{|c|}{86} & \multicolumn{2}{|c|}{100} \\
\hline
\end{tabular}

Met expression signature. First, the prevalence of the Met expression signature showed a significant association with aggressive phenotypic traits including increased MVD and rate of vascular invasion. These findings are in agreement with the observations that designated HGF/Met signaling as one of the key promoters of metastasis formation and tumor angiogenesis (16). Second, the presence of Met signature had major prognostic significance for the HCC patients as evidenced by 6 different supervised prediction algorithms applied to the independent training and validation sets of HCC samples. The analysis revealed a significantly lower survival rate for patients with the predicted presence of Met expression signature compared with the group with the absence of Met signature. Third, the Met signature included the target genes with strong cross-species conservation. These genes support the Metregulated cellular programs associated with neoplastic transformation and may therefore constitute important therapeutic targets. Genes involved in focal adhesion formation, as well as in the organization of actin cytoskeleton at the leading edge of a motile cell, are good examples of these functionally related target genes. Finally, the observation that the colon metastatic tumor samples shared the hepatocyte-specific Met expression signature suggests a considerable overlap of Met target genes induced during the progression of carcinomas with a different cellular origin.

The use of WT and Met KO primary hepatocyte cultures provided a significant advantage over experiments conducted on cell lines. Transcriptional response of cultured hepatocytes closely mimicked the in vivo events following HGF stimulation. Moreover, the comparison with Met KO cells allowed us to eliminate the HGF-independent cross-activation of the Met receptor by semaphorin/plexin B1 (50) or EGF/EGFR complexes (51) or by other mechanisms and therefore led to a more stringent detection of HGF target genes.

Nevertheless, it is highly likely that in human liver tumors the Met-regulated expression signature is not always associated with the alteration of the receptor itself. Activation of the HGF/Met pathway at different levels could produce the same expression patterns. There is also a possibility that distinct but functionally homologous signaling pathways could induce the same effector genes as HGF/Met. In this case, the shared expression signatures would reflect common phenotypic changes but different regulatory mechanisms. EGF and TGF- $\alpha$ are likely candidates, since they induce similar intracellular signaling events and cellular responses to Met (51). Comparison of LEC human HCCs with HCC samples from the different transgenic mouse models showed that human tumors with a bad prognosis were the most similar to MYC/TGF- $\alpha$ mouse tumors, suggesting the dominance of TGF- $\alpha$ /EGFR signaling in these samples (38). Thus, some of the Met target genes may be cross-regulated by the TGF- $\alpha$ /EGFR pathway or other tyrosine kinases. Currently, little information is available on the extent of overlap between the expression signatures of different tyrosine kinase pathways. However, previous studies suggested that activation of EGFR receptor could lead to direct transactivation of the Met in transformed cells. It is therefore possible, at least under certain conditions, that target genes specific for Met activation could be induced by the EGFR signaling (52). On the other hand, when similarities between HGF- and VEGF-induced expression profiles were investigated in endothelial cells, the data did not show a close resemblance between the 2 gene sets (53).

We believe that changes detected in gene expression can also provide mechanistic explanations for the phenotypic alterations observed in $\mathrm{KO}$ hepatocytes. Absence of induction of genes involved in motility and cytoskeletal organization correlates well with previously reported defects in KO cells such as impaired motility and decreased proliferation potential (20). A significant new finding in this study was the identification of the effect of Met activation on cellular homeostasis. Numerous genes participating in oxidative and xenobiotic stress response (Ephx1, Aldh1a1, Aldh1a7) or related to glutathione metabolism (Gsta3, Gstm3, Gclc) had elevated expression levels in Met KO cells. Most of them are 
A
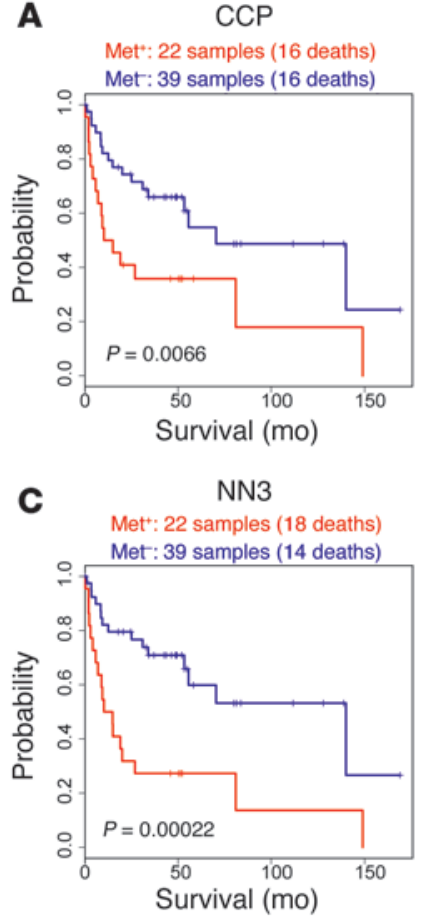

SVM
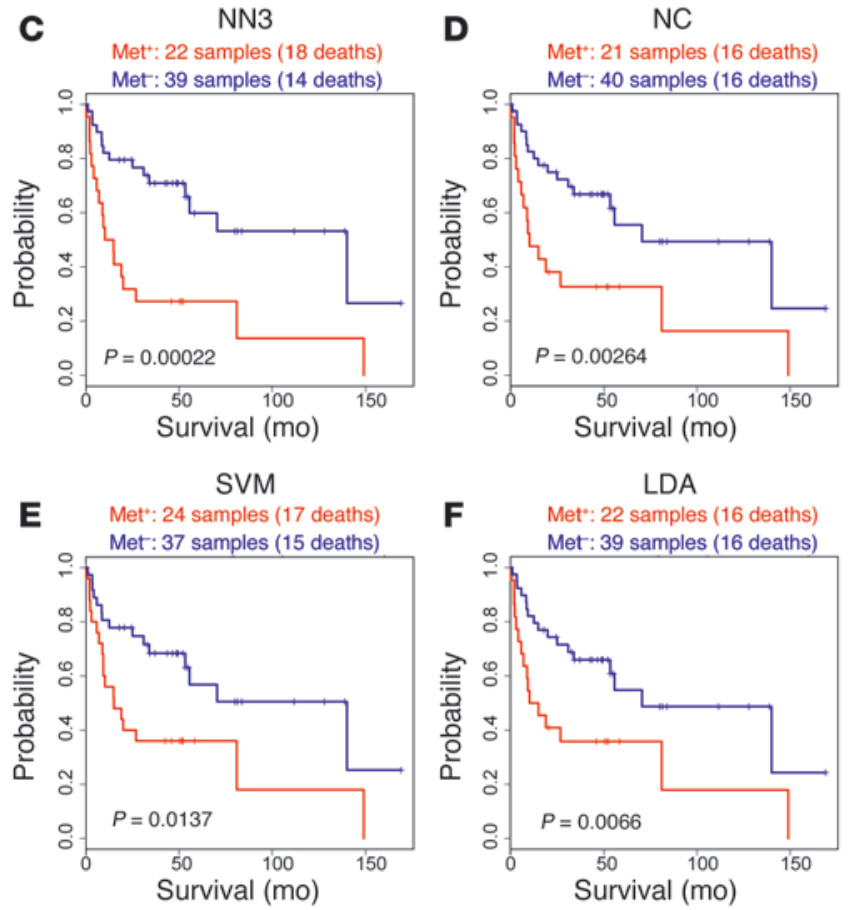

LDA
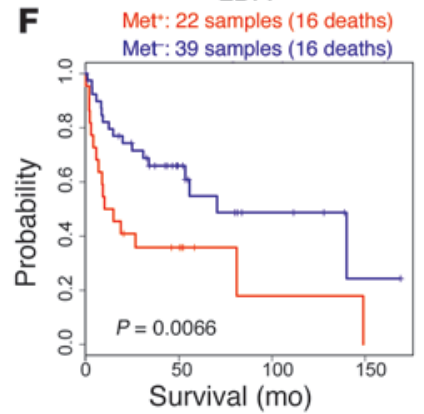

well-established targets of $\mathrm{Nfe} 212$ transcription factor (54), as they contain antioxidant response element in their promoter sequence. Although this pathway is essential for the detoxification of toxic metabolic intermediates, the permanent activation of $\mathrm{Nfe} 212$ in a mouse model is lethal (32). A connection between the Nfe212 and Met pathways could exist at multiple levels. Activation of ERK signaling by Met may inhibit retinoic X receptor $\alpha(R X R \alpha)(55)$, which together with $P P A R \gamma$ positively regulates $\mathrm{Nfe} 2 \mathrm{l} 2$ targets and lipid metabolic enzymes (56). Alternatively, elevated oxidative stress together with accumulation of toxic metabolic intermediates in Met $\mathrm{KO}$ animals may cause the high Nfe2l2 activation (32). Together these data implicate HGF/Met signaling as an important regulator of metabolic homeostasis in hepatocytes.

In conclusion, our study demonstrates that characterization of pathway-specific gene expression signatures in well-suited experimental models facilitates the discovery of novel intracellular regulatory mechanisms and can improve the molecular classification of human cancers.

\section{Methods}

Animal model. Hepatocyte-specific deletion of exon 16, essential for Met function, was achieved by crossing of the albumin-Cre transgene against the floxed

\section{Figure 7}

Survival analysis based on the predicted Met activation in the LEC validation set. Log-rank test results and Kaplan-Meier plots demonstrate the overall survival of HCC patients from the LEC validation set. Patients were stratified into 2 groups based on the expression pattern of preselected classifier genes using the CCP (A), NN1 (B), NN3 (C), NC (D), SVM (E), and LDA (F) algorithms. In the tumors from the Met $^{+}$ patients, higher activation of the Met signaling pathway is predicted compared with that in the Met group.

Met allele as described previously (18). The genotypes of the control and mutant mice used in this study were $\mathrm{Met}^{+++} \mathrm{AlbCre}^{+/-}$and $\mathrm{Met}^{-/-} \mathrm{AlbCre}{ }^{+-}$, respectively. All animal experiments were conducted according to the NIH guidelines for animal care. All animal experiments and procedures were approved by the National Cancer Institute Animal Care and Use Committee.

Hepatocyte isolation and culture. Hepatocytes were isolated by 2 -step collagenase perfusion of the mouse livers followed by isodensity purification in Percoll gradient (57). Cells were seeded at $2 \times 10^{6}$ in $10-\mathrm{cm}$ dishes in the plating medium supplemented with $10 \%$ FBS as described in ref. 57. After 4 hours, the plating medium was replaced with serum-free medium. The following day, cells were treated with $50 \mathrm{ng} / \mathrm{ml}$ of recombinant human HGF (PeproTech) for $0.5,2,12$, and 24 hours. Triplicate cell cultures were established from 3 individual mice. Cells without treatment were collected at the beginning of each time course experiment and served as 0 time control.

$R N A$ isolation and microarray bybridization. The Mouse OligoLibrary Release 1 plus Extension oligonucleotide set containing 21,997 65-mer oligonucleotides representing 19,740 unique genes was purchased from Compugene Inc. Microarrays were produced in the Laboratory of Molecular Technology, National Cancer Institute. Total RNA was extracted from the primary cultures using TRIZOL (Invitrogen Corp.) protocol. Each sample was hybridized against a common reference sample isolated from B6/129 WT primary hepatocytes, in a reverse-fluor design, and gene expression values were defined as a target-per-reference ratio. Twenty micrograms of total RNA was used to synthesize fluorescently labeled (Amersham Biosciences) cDNA probes. Preparation of the labeled cDNA samples and hybridization of oligonucleotide microarrays were performed with small modifications (37). Briefly, RNA samples were denaturated with $4 \mu \mathrm{g}$ (d)T20 primer at $70^{\circ} \mathrm{C}$ for 5 minutes, chilled on ice, and incubated for 1 hour at $42^{\circ} \mathrm{C}$ in a $50-\mu 1$ reaction mix containing $10 \mu 1$ 10x First-Strand buffer (Invitrogen Corp.), $2.5 \mu \mathrm{l} 20 \times$ deoxynucleotide triphosphate (dNTP) mix (10 mM dATP, dGTP, and CTP; $4 \mathrm{mM}$ dTTP; and $6 \mathrm{mM}$ aminoallyl-dUTP; Sigma-Aldrich), $5 \mu \mathrm{l}$ of $0.1 \mathrm{M}$ DTT, $2 \mu \mathrm{l}$ SuperScript II (Invitrogen Corp.) reverse transcriptase, and $1 \mu$ l SUPERaseIn (Ambion Inc.). After digestion with $4 \mathrm{U}$ RNase $\mathrm{H}$ (Ambion Inc.) at $37^{\circ} \mathrm{C}$ for 20 minutes, the samples were cleaned up with a MinElute PCR Purification Kit (QIAGEN). The eluted cDNA samples were concentrated by Speed Vac (Global Medical Instrumentation Inc.) and resolved in $20 \mu \mathrm{l} 0.1 \mathrm{M} \mathrm{NaHCO}_{3}$ solution. The $\mathrm{Cy} 3$ and $\mathrm{Cy} 5$ dyes (Amersham Biosciences) were also dissolved in $20 \mu \mathrm{l}$ of water. For the coupling reaction, $2 \mu \mathrm{l}$ of dye was added to each sample, and the mix was left in a dark box for an hour. Labeled cDNA was purified again with a MinElute kit (QIAGEN), and Cy3- and Cy5-labeled target and reference samples were combined. Before the hybridization, oligonucleotide microarrays were pretreated with a $5 \times$ SSC, $1 \%$ BSA, $0.1 \%$ SDS blocking solution. The samples were applied on the microarray slides in a hybridization mix containing $25 \%$ formamide, $0.1 \% \mathrm{SDS}$, and $5 \times \mathrm{SSC}$ in $28 \mu \mathrm{l}$ final volume. After overnight incubation, the slides were washed in a $1 \times$ SSC $0.1 \%$ SDS solution for 2 minutes and then consecutively in $1 \times$ SSC and $0.2 \times$ SSC solutions. Air-dried arrays were scanned in a GenePix 4000A scanner (Molecular Devices) in such a way that photomultiplier tube voltage was adjusted to achieve optimal signal intensity at both channels with less than $1 \%$ saturated spots. Image analysis was 
Table 4

Expression of selected classifier genes in HCC subclasses

\begin{tabular}{|c|c|c|c|c|c|c|}
\hline Gene symbo & Description & $\begin{array}{l}\text { Expression ratios } \\
\text { in } \text { Met+ }^{+} \text {class }\end{array}$ & $\begin{array}{l}\text { Expression ratios } \\
\text { in Met- class }\end{array}$ & $\begin{array}{l}\text { UniGene } \\
\text { ID }\end{array}$ & $t$ value & $\begin{array}{c}\text { Parametric } \\
P \text { value }\end{array}$ \\
\hline \multicolumn{7}{|c|}{ Cell motility, metastasis formation } \\
\hline CAP1 & CAP, adenylate cyclase-associated protein 1 & 1.229 & 0.582 & Hs.370581 & 4.56 & 0.000027 \\
\hline$A R P C 1 B$ & Actin-related protein $2 / 3$ complex, subunit $1 \mathrm{~B}$ & 1.234 & 0.641 & Hs.489284 & 3.85 & 0.000293 \\
\hline TUBB6 & Tubulin $\beta 6$ & 1.616 & 0.702 & Hs.193491 & 4.52 & 0.000032 \\
\hline ITGB1 & Integrin $\beta 1$ & 1.531 & 0.68 & Hs.429052 & 4.51 & 0.000042 \\
\hline NCK2 & NCK adaptor protein 2 & 1.806 & 0.736 & Hs. 529244 & 5.24 & 0.000004 \\
\hline ITGAV & Integrin $\alpha \mathrm{V}$ & 1.664 & 0.752 & Hs. 436873 & 4.06 & 0.000148 \\
\hline FGD6 & FYVE, RhoGEF and PH domain-containing 6 & 1.709 & 0.868 & Hs. 506381 & 3.52 & 0.000894 \\
\hline MDFI & MyoD family inhibitor & 1.665 & 0.889 & Hs. 520119 & 3.82 & 0.000381 \\
\hline PIK3R1 & Phosphatidylinositol 3-kinase, regulatory subunit 1 & 0.565 & 1.33 & Hs. 132225 & -5.58 & $<0.000001$ \\
\hline ANXA5 & Annexin A5 & 1.344 & 0.605 & Hs. 480653 & 4.76 & 0.000014 \\
\hline \multicolumn{7}{|c|}{ Cell proliferation } \\
\hline CKS2 & CDC28 protein kinase, regulatory subunit 2 & 1.568 & 0.695 & Hs.83758 & 5.45 & 0.000001 \\
\hline MAPK3 & Mitogen-activated protein kinase 3 & 1.548 & 0.74 & Hs.861 & 4.17 & 0.000102 \\
\hline KPNB1 & Karyopherin (importin) $\beta 1$ & 1.467 & 0.705 & Hs. 532793 & 4.7 & 0.000016 \\
\hline STK25 & Serine/threonine kinase 25 & 1.551 & 0.761 & Hs. 516807 & 4.04 & 0.000161 \\
\hline PLCE1 & Phospholipase Cع1 & 1.353 & 0.61 & Hs.549158 & 4.88 & 0.000009 \\
\hline DENR & Density-regulated protein & 1.647 & 0.69 & Hs.22393 & 6.84 & $<0.000001$ \\
\hline \multicolumn{7}{|l|}{ Prognosis } \\
\hline HMGA1 & High-mobility group AT-hook 1 & 1.541 & 0.587 & Hs. 518805 & 6.29 & $<0.000001$ \\
\hline CD63 & CD63 antigen & 1.35 & 0.644 & Hs. 445570 & 4.5 & 0.000034 \\
\hline HIG2 & Hypoxia-inducible protein 2 & 1.511 & 0.726 & Hs.521171 & 3.88 & 0.000319 \\
\hline \multicolumn{7}{|c|}{ Stress response } \\
\hline$A L D H 1 A 1$ & Aldehyde dehydrogenase 1 family, member $\mathrm{A} 1$ & 0.558 & 1.095 & Hs.76392 & -4 & 0.000183 \\
\hline ALDH6A1 & Aldehyde dehydrogenase 6 family, member A1 & 0.504 & 1.378 & Hs.293970 & -7.38 & $<0.000001$ \\
\hline EPHX1 & Epoxide hydrolase 1 & 0.466 & 1.143 & Hs.89649 & -7.47 & $<0.000001$ \\
\hline EPHX2 & Epoxide hydrolase 2 & 0.537 & 1.285 & Hs.212088 & -5.71 & $<0.000001$ \\
\hline GSTT1 & Glutathione-S-transferase $\theta 1$ & 0.72 & 1.27 & Hs.268573 & -3.76 & 0.000418 \\
\hline
\end{tabular}

performed with GenePix Pro 5.1.0.11 software (Molecular Devices), following the manufacturer's recommendations.

Real-time RT-PCR experiments. Real-time PCR quantification of mRNA levels for 10 selected HGF/Met target genes was performed on the same RNA samples that we used for microarray hybridization. After DNase digestion with a DNA-free kit (Ambion Inc.), $3 \mu \mathrm{g}$ total RNA was reverse transcribed in $20 \mu \mathrm{l}$ reaction volume with a SuperScript (Invitrogen Corp.) first-strand synthesis kit according to the manufacturer's instructions. The real-time quantitative PCR analysis was performed with an ABI PRISM 7900HT (Applied Biosystems) thermal cycler in a 96-well reaction plate. The 25- $\mu$ l PCR reaction mix contained $12.5 \mu \mathrm{l} 2 \times$ SYBR Green PCR Master Mix (Applied Biosystems), $400 \mathrm{nM}$ of each primer, and $1 \mu \mathrm{l}$ cDNA template. Reactions were incubated for 10 minutes at $95^{\circ} \mathrm{C}$ followed by 40 cycles of 30 seconds at $95^{\circ} \mathrm{C}$ and 60 seconds at $60^{\circ} \mathrm{C}$. Melting analysis of the PCR products was also conducted to validate the amplification of the specific product. The expression level of mouse $\beta_{2}$-microglobulin was used as an internal reference. Relative gene expression levels were calculated with the $2^{-\Delta \Delta C T}$ method (58). Primer sequences together with expected product length are listed in Table 5.

Immunohistochemistry and calculation of MVD. Detection of protein expression levels of human Met receptor and CD34 surface antigen was performed on representative human HCC samples from the subgroups with or without Met activation signature (12 samples each). For immunohistochemistry, 5 - $\mu$ m-thick sections were cut from $10 \%$ formalinfixed, paraffin-embedded tissues. Sections were routinely deparaffinized, and endogenous peroxidase was blocked with $3 \% \mathrm{H}_{2} \mathrm{O}_{2}$ for 20 minutes.
Antigen retrieval was performed by placing samples into boiling citrate buffer ( $\mathrm{pH}$ 6.0) for 20 minutes. Sections were blocked for 30 minutes with $10 \%$ serum, then incubated overnight at $4^{\circ} \mathrm{C}$ with a $1: 100$ dilution of anti-human MET (Santa Cruz Biotechnology Inc.) or anti-CD34 (Zymed Laboratories Inc.) antibodies. For visualization of the specific staining, VECTASTAIN ABC Elite kits (Vector Laboratories) and diaminobenzidine peroxidase substrate (Dako) were used. Slides were counterstained with hematoxylin. The staining intensities for Met were classified as weak (+), intermediate $(++)$, or strong $(+++)$. At least 10 visual fields were assessed for each specimen with $\times 200$ magnification.

MVD was determined by CD34 immunostaining in 12 representative samples from both the $\mathrm{Met}^{+}$and Met- subclasses in the LEC set. The density of $\mathrm{CD} 34^{+}$features was determined in 5 angiogenetic "hot spots" in each sample using Image-Pro Plus version 3 (MediaCybernetics) software. MVD was expressed as mean $\mathrm{OD} \pm$ SEM per visual field. Two-tailed Student's $t$ test was used to compare tumor vessel density. The differences were considered statistically significant with $P<0.01$.

Data analysis for identification of HGF/Met expression signature. First, image spots with diameter less than $10 \mu \mathrm{m}$ or more than $300 \mu \mathrm{m}$ or signal intensity below background intensity for any of the 2 fluorescent channels were excluded. Only genes with at least 4 data points out of 6 experiments in at least 2 experimental groups in the mouse primary hepatocyte data set were selected for further data analysis. Gene expression values were normalized by median-centering log ratios across all primary hepatocyte samples. For each spot, the target-per-reference intensity ratio was $\log _{2}$ transformed and averaged between duplicate experiments. 


\section{Table 5}

Primers used in real-time PCR experiments

\begin{tabular}{|c|c|c|}
\hline Gene & GenBank & Product \\
\hline Adenylate cyclase-associated protein 1 (Cap1) & NM_007598 & $101 \mathrm{bp}$ \\
\hline \multicolumn{3}{|l|}{ Forward: 5'-GACAGCCCTTCAAAAGGAGCA-3' } \\
\hline \multicolumn{3}{|l|}{ Reverse: 5'-CCCCCGATCTCCTTACTCATCT-3' } \\
\hline Aldehyde dehydrogenase 1 family, member $A 1$ (Aldh1a1) & NM_013467 & $215 b$ \\
\hline \multicolumn{3}{|l|}{ Forward: 5'-CCTGCAACTGAGGAGGTCAT-3' } \\
\hline \multicolumn{3}{|l|}{ Reverse: 5'-ACTTTCCCACCATTGAGTGC-3' } \\
\hline$\beta_{2}$-Microglobulin $(B 2 m)$ & NM_009735 & 252 \\
\hline \multicolumn{3}{|l|}{ Forward: 5'-ATGGGAAGCCGAACATACTGAA-3' } \\
\hline \multicolumn{3}{|l|}{ Reverse: 5'-ATCACATGTCTCGATCCCAGTA-3' } \\
\hline Cadherin 17 (Cdh17) & NM_019753 & $176 b$ \\
\hline \multicolumn{3}{|l|}{ Forward: 5'-ATCACTCAGGTGCAGTGGAA-3' } \\
\hline \multicolumn{3}{|l|}{ Reverse: 5'-CCATTCTCATCCTTGGCAGT-3' } \\
\hline Glutathione-S-transferase $\alpha 1$ (Gsta1) & NM_008181 & 153 \\
\hline \multicolumn{3}{|l|}{ Forward: 5'-CCCCTTTCCCTCTGCTGAAG-3' } \\
\hline \multicolumn{3}{|l|}{ Reverse: 5'-TGCAGCTTCACTGAATCTTGAAAG-3' } \\
\hline Glutathione-S-transferase $\mu 3$ (Gstm3) & NM_010359 & $213 \mathrm{bp}$ \\
\hline \multicolumn{3}{|l|}{ Forward: 5'-TATGACACTGGGCTATTGGAACAC-3' } \\
\hline \multicolumn{3}{|l|}{ Reverse: 5'-CTCTGGGTGACCTTGTGTGA-3' } \\
\hline Glycine- $C$-acyltransferase (Gcat) & NM_013847 & 137 \\
\hline \multicolumn{3}{|l|}{ Forward: 5'-GGAGGCTCAGAAGCACAGG-3' } \\
\hline \multicolumn{3}{|l|}{ Reverse: 5'-CATGGCATTCATCCACAAAG-3' } \\
\hline \multirow{2}{*}{\multicolumn{3}{|c|}{ Forward: 5'-ATGCCGAAGACGATCAGTGTG-3' }} \\
\hline & & \\
\hline \multicolumn{3}{|l|}{ Reverse: 5'-TTGGCCCGGAACTTGAAGA-3' } \\
\hline Nuclear factor (erythroid-derived 2)-like 2 (Nfe2/2) & NM_010902 & 104 \\
\hline \multicolumn{3}{|l|}{ Forward: 5'-ATGCAGCTTTTGGCAGAGAC-3' } \\
\hline \multicolumn{3}{|l|}{ Reverse: 5'-TGATGAGGGGCAGTGAAGAC-3' } \\
\hline Osteopontin (Spp1) & NM_009263 & 170 \\
\hline \multicolumn{3}{|l|}{ Forward: 5'-TCTGATGAGACCGTCACTGC-3' } \\
\hline \multicolumn{3}{|l|}{ Reverse: 5'-AGGTCCTCATCTGTGGCATC-3' } \\
\hline Phosphatidylinositol 3-kinase, regulatory subunit 1 (Pik3r1) & NM_011085 & 184 \\
\hline Forward: 5'-GACCAATACTTGATGTGGCTGA-3' & & \\
\hline Reverse: 5'-GCAATAGGTTCTCCGCTTTG-3' & & \\
\hline
\end{tabular}

available clinical information, is available in previous publications (35-37). In our analysis we selected genes represented on both the mouse and the human platform using curated mammalian orthologs from Jackson Laboratory. We found 440 common orthologs of the Met-regulated genes in the LEC set and 303 genes in the Stanford sets. Before collation of data into 2 mixed mouse-human sets, gene expression ratios were normalized separately on the different microarray platforms with mean set to 0 and SD to 1 for each gene (38). Hierarchical cluster analysis based on Pearson correlation was performed with Cluster 2.11, and results were visualized with TreeView programs (Michael Eisen Laboratory, Lawrence Berkeley National Laboratory and University of California, Berkeley; http://rana.lbl.gov/ EisenSoftware.htm).

We used 6 algorithms, the CCP, NN1, NN3, NC, SVM, and LDA (BRB ArrayTools; Biometric Research Branch, National Cancer Institute), to perform the class prediction analysis with the Met target genes. The LEC data set was randomly divided into a training set (60 samples) and a prediction set (79 samples). To build an optimized classifier list, which could estimate the probability of the identity of a particular sample, we used an LOOCV approach. During the cross-validation step, 1 sample was removed from the analysis, and the remaining samples were used to identify the most differentially expressed genes between the groups. Based on expression of these genes, identity of the left-out sample was predicted with a given algorithm. This process was repeated until each sample was left out once. The number of genes in the classifier was varied to provide the highest correct prediction rate in the training set. To estimate accuracy of the prediction model, class labels were randomly permuted, and the LOOCV process was repeated 1,000 times. The significance level is the proportion of the random permutations that gave a cross-validated error rate no greater than the cross-validated error rate obtained with the real data. The 6 classification methods were also applied

Genes differentially expressed between groups of Met KO and Cre-control hepatocyte samples were identified by a multivariate permutation $t$ test using the BRB ArrayTools 3.3 software package (Biometric Research Branch, National Cancer Institute; http://linus.nci.nih.gov/BRB-ArrayTools.html). We set parameters in the multivariate permutation test to provide $90 \%$ confidence level at false discovery rate less than $10 \%$ after 1,000 random permutations. Selection criteria for individual genes included a significance level of $P<0.001$ in the univariate $t$ test plus more than 1.5 -fold expression difference between the compared groups. Selected significant genes were further divided into subgroups based on their temporal expression pattern. The group of permanently different genes contained genes whose expression was significantly different $(P<0.005)$ between the 2 genotypes by univariate $t$ test at 0 hour plus at least 1 early ( 0.5 or 2 hours) and 1 late (12 or 24 hours) treatment point. The rest of the significant genes were classified as early or late up- or downregulated genes based on the treatment point at which they showed the most significant regulation by HGF.

For comparison of the Met signature in human HCC and mouse hepatocytes, we used 2 independent human HCC microarray data sets. The LEC set was generated in our laboratory (37) and contained expression profiles from 139 HCC samples. The other data set was obtained from the Stanford University microarray database (http://genome-www5.stanford. $\mathrm{edu} /$ ) and included 103 human HCC samples and 7 liver metastases from extrahepatic tumors. Detailed analysis of the human data sets, as well as to the LEC validation set, and survival analysis was performed to assess the clinical significance of predicted HCC groups. Prediction of the metastases in the Stanford data set was performed in a similar manner using the same LEC training set but only with Met target genes commonly available on both platforms. Survival analysis was based on predicted presence or absence of Met activation-based hierarchical clustering or different prediction algorithms. Kaplan-Meier survival analysis and log-rank test were performed with the R 1.8.1 statistical package (http://www.r-project.org/).

We thank Joe Grisham and Liz Conner for their comments and critical review of the manuscript and Stephen Wincovitch for his help in image analysis. This research was supported in part by the Intramural Research Program of the Center for Cancer Research.

Received for publication October 26, 2005, and accepted in revised form March 7, 2006.

Address correspondence to: Snorri S. Thorgeirsson, Laboratory of Experimental Carcinogenesis, National Cancer Institute, National Institutes of Health, 37 Convent Drive, Building 37, Room 4146, Bethesda, Maryland 20892, USA. Phone: (301) 496-5688; Fax: (301) 496-0734; E-mail: snorri_s_thorgeirsson@nih.gov.

\section{Acknowledgments}


1. Rhodes, D.R., and Chinnaiyan, A.M. 2005. Integrative analysis of the cancer transcriptome. Nat. Genet. 37(Suppl.):S31-S37.

2. Rhodes, D.R., et al. 2004. ONCOMINE: a cancer microarray database and integrated data-mining platform. Neoplasia. 6:1-6.

3. Rhodes, D.R., et al. 2004. Large-scale meta-analysis of cancer microarray data identifies common transcriptional profiles of neoplastic transformation and progression. Proc. Natl. Acad. Sci. U. S. A 101:9309-9314.

4. Segal, E., Friedman, N., Kaminski, N., Regev, A., and Koller, D. 2005. From signatures to models: understanding cancer using microarrays. Nat. Genet. 37(Suppl.):S38-S45.

5. Sweet-Cordero, A., et al. 2005. An oncogenic KRAS2 expression signature identified by cross-species gene-expression analysis. Nat. Genet. 37:48-55.

6. Huang, E., et al. 2003. Gene expression phenotypic models that predict the activity of oncogenic pathways. Nat. Genet. 34:226-230.

7. Furge, K.A., Zhang, Y.W., and Vande Woude, G.F. 2000. Met receptor tyrosine kinase: enhanced signaling through adapter proteins. Oncogene. 19:5582-5589.

8. Gentile, A., and Comoglio, P.M. 2004. Invasive growth: a genetic program. Int. J. Dev. Biol. 48:451-456

9. Schmidt, C., et al. 1995. Scatter factor/hepatocyte growth factor is essential for liver development. Nature. 373:699-702.

10. Bladt, F., Riethmacher, D., Isenmann, S., Aguzzi, A., and Birchmeier, C. 1995. Essential role for the c-met receptor in the migration of myogenic precursor cells into the limb bud. Nature. 376:768-771.

11. Michalopoulos, G.K., and DeFrances, M.C. 1997. Liver regeneration. Science. 276:60-66.

12. Ueki, T., et al. 1999. Hepatocyte growth factor gene therapy of liver cirrhosis in rats. Nat. Med. 5:226-230.

13. Schulze-Bergkamen, H., et al. 2004. Hepatocyte growth factor induces Mcl-1 in primary human hepatocytes and inhibits CD95-mediated apoptosis via Akt. Hepatology. 39:645-654.

14. Wang, X., et al. 2002. A mechanism of cell survival: sequestration of Fas by the HGF receptor Met. Mol. Cell. 9:411-421.

15. Stolz, D.B., Mars, W.M., Petersen, B.E., Kim, T.H., and Michalopoulos, G.K. 1999. Growth factor signal transduction immediately after two-thirds partial hepatectomy in the rat. Cancer Res. 59:3954-3960.

16. Birchmeier, C., Birchmeier, W., Gherardi, E., and Vande Woude, G.F. 2003. Met, metastasis, motility and more. Nat. Rev. Mol. Cell Biol. 4:915-925.

17. Ma, P.C., Maulik, G., Christensen, J., and Salgia, R. 2003. c-Met: structure, functions and potential for therapeutic inhibition. Cancer Metastasis Rev. 22:309-325.

18. Corso, S., Comoglio, P.M., and Giordano, S. 2005. Cancer therapy: can the challenge be MET? Trends Mol. Med. 11:284-292.

19. Ueki, T., Fujimoto, J., Suzuki, T., Yamamoto, H., and Okamoto, E. 1997. Expression of hepatocyte growth factor and its receptor c-met proto-oncogene in hepatocellular carcinoma. Hepatology. 25:862-866.

20. Huh, C.G., et al. 2004. Hepatocyte growth factor/ c-met signaling pathway is required for efficient liver regeneration and repair. Proc. Natl. Acad. Sci. U. S. A. 101:4477-4482.

21. Medico, E., et al. 2001. Osteopontin is an autocrine mediator of hepatocyte growth factor-induced invasive growth. Cancer Res. 61:5861-5868.
22. Gujdar, A., Sipeki, S., Bander, E., Buday, L., and Farago, A. 2004. Protein kinase C modulates negatively the hepatocyte growth factor-induced migration, integrin expression and phosphatidylinositol 3-kinase activation. Cell. Signal. 16:505-513.

23. Recio, J.A., and Merlino, G. 2003. Hepatocyte growth factor/scatter factor induces feedback upregulation of CD44v6 in melanoma cells through Egr-1. Cancer Res. 63:1576-1582.

24. Lipschutz, J.H., Li, S., Arisco, A., and Balkovetz, D.F. 2005. Extracellular signal-regulated kinases $1 / 2$ control claudin- 2 expression in Madin-Darby canine kidney strain I and II cells. J. Biol. Chem. 280:3780-3788.

25. Baron, V., Adamson, E.D., Calogero, A., Ragona, G., and Mercola, D. 2006. The transcription factor Egr1 is a direct regulator of multiple tumor suppressors including TGFbeta1, PTEN, p53, and fibronectin. Cancer Gene Ther. 13:115-124.

26. Kempiak, S.J., et al. 2005. A neural Wiskott-Aldrich Syndrome protein-mediated pathway for localized activation of actin polymerization that is regulated by cortactin. J. Biol. Chem. 280:5836-5842.

27. Moriyama, K., and Yahara, I. 2002. Human CAP1 is a key factor in the recycling of cofilin and actin for rapid actin turnover. J. Cell Sci. 115:1591-1601.

28. McClatchey, A.I. 2003. Merlin and ERM proteins: unappreciated roles in cancer development? Nat. Rev. Cancer. 3:877-883.

29. Guo, W., and Giancotti, F.G. 2004. Integrin signalling during tumour progression. Nat. Rev. Mol. Cell Biol. 5:816-826

30. Wai, P.Y., and Kuo, P.C. 2004. The role of Osteopontin in tumor metastasis. J. Surg. Res. 121:228-241.

31. Dickinson, D.A., et al. 2004. Human glutamate cysteine ligase gene regulation through the electrophile response element. Free Radic. Biol. Med. 37:1152-1159.

32. Motohashi, H., and Yamamoto, M. 2004. Nrf2Keap1 defines a physiologically important stress response mechanism. Trends Mol. Med. 10:549-557.

33. Dhakshinamoorthy, S., and Jaiswal, A.K. 2000. Small maf (MafG and MafK) proteins negatively regulate antioxidant response element-mediated expression and antioxidant induction of the $\mathrm{NAD}(\mathrm{P}) \mathrm{H}: \mathrm{Quinone}$ oxidoreductase1 gene. J. Biol. Chem. 275:40134-40141.

34. Stahl, S., et al. 2005. Genotype-phenotype relationships in hepatocellular tumors from mice and man. Hepatology. 42:353-361.

35. Lee, J.S., et al. 2004. Classification and prediction of survival in hepatocellular carcinoma by gene expression profiling. Hepatology. 40:667-676.

36. Lee, J.-S., et al. 2006. A novel prognostic subtype of human hepatocellular carcinoma derived from hepatic progenitor cells. Nat. Med. 12:410-416.

37. Chen, X., et al. 2002. Gene expression patterns in human liver cancers. Mol. Biol. Cell. 13:1929-1939.

38. Lee, J.S., et al. 2004. Application of comparative functional genomics to identify best-fit mouse models to study human cancer. Nat. Genet. 36:1306-1311.

39. Strohmeyer, D., et al. 2004. Expression of bFGF, VEGF and c-met and their correlation with microvessel density and progression in prostate carcinoma. Anticancer Res. 24:1797-1804.

40. Kuhnen, C., et al. 2003. Impact of c-Met expression on angiogenesis in soft tissue sarcomas: correlation to microvessel-density. J. Cancer Res. Clin. Oncol. 129:415-422

41. Denko, N., et al. 2000. Epigenetic regulation of gene expression in cervical cancer cells by the tumor microenvironment. Clin. Cancer Res. 6:480-487.

42. Kinch, M.S., and Carles-Kinch, K. 2003. Overex- pression and functional alterations of the EphA2 tyrosine kinase in cancer. Clin. Exp. Metastasis. 20:59-68.

43. MacDonald, T.J., et al. 2001. Expression profiling of medulloblastoma: PDGFRA and the RAS/MAPK pathway as therapeutic targets for metastatic disease. Nat. Genet. 29:143-152.

44. Bardelli, A., et al. 1999. Concomitant activation of pathways downstream of Grb2 and PI 3-kinase is required for MET-mediated metastasis. Oncogene. 18:1139-1146.

45. Pollard, T.D., and Borisy, G.G. 2003. Cellular motility driven by assembly and disassembly of actin filaments. Cell. 112:453-465.

46. Sherman, M. 2005. Hepatocellular carcinoma: epidemiology, risk factors, and screening. Semin. Liver Dis. 25:143-154.

47. Okabe, H., et al. 2001. Genome-wide analysis of gene expression in human hepatocellular carcinomas using cDNA microarray: identification of genes involved in viral carcinogenesis and tumor progression. Cancer Res. 61:2129-2137.

48. Iizuka, N., et al. 2003. Oligonucleotide microarray for prediction of early intrahepatic recurrence of hepatocellular carcinoma after curative resection. Lancet. 361:923-929.

49. Ye, Q.H., et al. 2003. Predicting hepatitis B viruspositive metastatic hepatocellular carcinomas using gene expression profiling and supervised machine learning. Nat. Med. 9:416-423.

50. Giordano, S., et al. 2002. The semaphorin 4D receptor controls invasive growth by coupling with Met. Nat. Cell Biol. 4:720-724.

51. Fischer, O.M., Giordano, S., Comoglio, P.M., and Ullrich, A. 2004. Reactive oxygen species mediate Met receptor transactivation by G protein-coupled receptors and the epidermal growth factor receptor in human carcinoma cells. J. Biol. Chem. 279:28970-28978.

52. Jo, M., et al. 2000. Cross-talk between epidermal growth factor receptor and c-Met signal pathways in transformed cells. J. Biol. Chem. 275:8806-8811.

53. Gerritsen, M.E., Tomlinson, J.E., Zlot, C., Ziman, M., and Hwang, S. 2003. Using gene expression profiling to identify the molecular basis of the synergistic actions of hepatocyte growth factor and vascular endothelial growth factor in human endothelial cells. Br. J. Pharmacol. 140:595-610.

54. Lee, J.M., Calkins, M.J., Chan, K., Kan, Y.W., and Johnson, J.A. 2003. Identification of the NF-E2related factor-2-dependent genes conferring protection against oxidative stress in primary cortical astrocytes using oligonucleotide microarray analysis. J. Biol. Chem. 278:12029-12038.

55. Matsushima-Nishiwaki, R., et al. 2003. Molecular mechanism for growth suppression of human hepatocellular carcinoma cells by acyclic retinoid. Carcinogenesis. 24:1353-1359.

56. Park, E.Y., Cho, I.J., and Kim, S.G. 2004. Transactivation of the PPAR-responsive enhancer module in chemopreventive glutathione S-transferase gene by the peroxisome proliferator-activated receptorgamma and retinoid $\mathrm{X}$ receptor heterodimer. Cancer Res. 64:3701-3713.

57. Kao, C.Y., Factor, V.M., and Thorgeirsson, S.S. 1996. Reduced growth capacity of hepatocytes from $\mathrm{c}-\mathrm{myc}$ and c-myc/TGF- $\alpha$ transgenic mice in primary culture. Biochem. Biophys. Res. Commun. 222:64-70.

58. Pfaffl, M.W., Horgan, G.W., and Dempfle, L. 2002. Relative expression software tool (REST) for groupwise comparison and statistical analysis of relative expression results in real-time PCR. Nucleic Acids Res. 30:e36. 